\title{
Ratings and Asset Allocation: An Experimental Analysis*
}

\author{
Robert L. McDonald ${ }^{\dagger} \quad$ Thomas A. Rietz ${ }^{\ddagger}$
}

July 16, 2017

\begin{abstract}
Investment ratings (e.g. by Morningstar) provide a simple ordinal measure to compare assets. Typically, ratings are assigned within categories - groupings in which assets share important characteristics. Comparing ratings across categories can be misleading. We study ratings using an asset allocation experiment focusing specifically on this problem. Subjects make repeated allocation decisions under complete information. Ratings that convey no new information and that are altered because of categorization affect subject investment choices and harm performance in the experiment.
\end{abstract}

${ }^{*}$ We thank the TIAA-CREF Institute for funding this research and Ying Xu for programming. For helpful comments we also thank Bruno Biais and two anonymous referees, Craig Furfine, Simon Gervais, Luigi Guiso, Ravi Jagannathan, Lisa Kramer, Cami Kuhnen, Owen Lamont, Daniel Martin, Olivia Mitchell, Brian Sternthal, Tom Vinaimont, seminar participants at the New York Fed, University of Iowa, University of Illinois, City University of Hong Kong, Hong Kong University, Hong Kong Polytechnic University, Korea University Business School, and conference participants at the Economic Science Association meetings, UBC, and the Wharton Conference on Household Finance.

${ }^{\dagger}$ Erwin P. Nemmers Professor of Finance, Kellogg School of Management, Northwestern University; TIAA-CREF Institute Fellow; and NBER. Contact: 847-491-8344, r-mcdonald@northwestern.edu

${ }^{\ddagger}$ Soumyo Sarkar Professor of Finance, Tippie College of Business, The University of Iowa; and TIAA-CREF Institute Fellow. Contact: 319-335-0856, thomas-rietz@uiowa.edu 


\section{Conflict of Interest Disclosures}

\section{Robert McDonald}

Robert McDonald is a member of the FINRA National Adjudicatory Council and a director of Eris Exchange. He receives compensation for both. Neither is a conflict of interest for this research.

\section{Thomas Rietz}

As part of TIAA's funding for this research, which included subject payments and development costs, Thomas Rietz received partial summer support for one summer. This is not a conflict of interest for this research. 


\section{Introduction}

Personal financial decisions are complicated and have ramifications that span decades. Investors face a variety of long-term risks and are confronted with numerous assets and investment strategies. Fully optimal portfolio decisions that take into account realistic extensions to the basic model (factoring in uncertain labor income, for example) are complicated in all but the simplest cases [e.g., see Merton, 1971, 1973].

To assist investors, institutions and advisers often present summary information about assets and portfolios, including summary rankings. As an example, Morningstar in 2016 rated mutual funds using 122 categories and 9 category groups. Funds in each category are rated using one to five stars (worst to best), and stars are assigned using a mandatory curve, based on risk-adjusted historical returns. ${ }^{1}$ Stars are not comparable across categories - a 5-star fund in "Equity Precious Metals" cannot be directly compared to a 3-star fund in "Trading-Inverse Equity." Because of the mandatory curve, star ratings can change when the funds in the category change. More importantly, optimal investment allocation decisions depend on the overall investment return and risk for the investor's entire portfolio. Categorized ratings, however, only compare performance to other investments of a similar style. The use of a common scale across categories may distort choices by making non-comparable items appear comparable.

Credit ratings create a similar issue. Rating agencies use a familiar ordinal system (AAA, AA, etc.) to describe the credit risk of both bonds and structured products, even though ratings are not meant to be comparable across categories.

We report on an experiment designed to assess the effects of such categorized ratings. In a setting with complete information about asset characteristics, subjects allocate $\$ 12$ across six

\footnotetext{
${ }^{1}$ Ten percent of funds in each category receive 5 stars and 1 star each, $22.5 \%$ receive 4 and 2 stars each, and $35 \%$ receive three stars. The original Morningstar ranking system was introduced in 1985, with all stock funds ranked in a common pool [Blume, 1998]. In 1996, category rankings were introduced. In 2002, smaller category groups were introduced [Morningstar, 2008]. Morningstar justified categorization as eliminating a "tail-wind" effect, in which specific industries or investment styles would by chance generate high returns and receive investor attention. By eliminating one problem, however, categorization could create a different problem, creating the appearance of comparability where there is none.
} 
investment alternatives, in multiple trials. Each of the investments has a binomial payoff that is perfectly correlated across the assets. Subjects have complete information about the assets at all times: the presentation in each trial includes the high and low returns for each investment, along with the mean return, range, and the return/range ratio. In comparing assets, therefore, subjects do not have to perform computations, think about diversification, or remember asset characteristics from one trial to the next. The existing literature has shown that individuals have limitations and behavioral biases in perception, attention, and cognitive ability, with differing abilities to to comprehend and act upon financial information; our design eliminates many computational and cognitive hurdles for subjects. Payoffs are revealed at the conclusion of the experiment, so there is no learning about returns, statistical inference, or income effect. Risk-averse investors should have an unambiguous preference for two of the assets; of the remaining four, two would only be optimal for risk seeking subjects and two have payoffs that are strictly dominated for any risk preference. Diversification across the six assets is suboptimal.

The main treatment is categorization. In the first trial, the assets have no ratings. Subjects are then shown star ratings, with half of subjects shown uncategorized ratings and the other half shown categorized ratings. Categorization alters the rating of four of the six assets, and reduces the rating of one of the assets that should be preferred by risk-averse subjects. We find that subjects exposed to categorized ratings hold less of the lower-rated optimal asset, and as a result perform more poorly. At the end of the experiment, subjects take a financial knowledge quiz, allowing us to correlate the knowledge score with behavior. Knowledgable subjects perform better but are still affected by categorization.

Subjects could be influenced by ratings for different reasons. One possibility is the so-called experimenter-demand effect Zizzo [2010], in which subjects respond to a cue such as star ratings because they believe they are supposed to do so. An alternative is that subjects are cognitively challenged, have difficulty with the experimental task, and use the ratings to assist them in decisionmaking. A third possibility is that subjects face cognitive dissonance when a rating is inconsistent 
with their prior belief about the asset and they respond to this dissonance by investing less, thereby harmonizing the rating and their behavior.

While all three explanations seem plausible, subject behavior does not align with the first two. Subjects perform reasonably well in the allocation task without ratings, suggesting cognitive ability with the task. When they are shown ratings, they do not change investment behavior on average except in the case where ratings are altered by categorization. This seems to rule out the experimenter demand effect, which in its strongest form would predict that subjects going from no stars to stars would invest more heavily in the highest rated assets and less in the lower-rated. The likeliest explanation seems to be dissonance induced by the inconsistency of categorized ratings with the belief about which assets were good.

While we defer a detailed discussion of the related literature until after we have presented our results, we note that the experiment touches on four distinct but related questions that have been discussed in the literature:

- How does the presentation of summary information and investment alternatives affect investment choices? This has been studied in the context of Morningstar ratings [Del Guercio and Tkac, 2008, Reuter and Zitzewitz, 2015], bond ratings [Chen et al., 2014], and in the study of menu effects [Bateman et al., 2016, Benartzi and Thaler, 2001, Huberman and Jiang, 2006, Massa et al., 2015]. ${ }^{2}$

- How do financial knowledge and experience affect investment behavior? Bernheim et al. [2001], Bernheim and Garrett [2003], Lusardi and Mitchell [2007], and Anderson and Settle [1996] all demonstrate effects of financial literacy.

- How do cognitive limitations affect decision making [Edgell et al., 1996, Thaler, 1980, Tversky and Kahneman, 1974, Camerer et al., 1989]?

- Can subjects make appropriate portfolio choice decisions [Moore et al., 1999, Kroll et al.,

\footnotetext{
${ }^{2}$ In the framework of Campbell [2006], ratings may be viewed as an example of "equilibrium household finance."
} 
1988, 2003]?

In Section 2, we describe the experiment. The actual experimental instructions are in Appendix B. Section 3 presents and discusses our results and treatment effects. We first examine subject behavior in the first, untreated trial. We then look at how behavior changed in response to treatments. We discuss related literature in Section 4 and throughout the paper as appropriate. Section 5 concludes.

\section{Experimental Design}

In this section, we describe the essential aspects of the experiment: the lottery choices that subjects face, the optimal choice among the lotteries, and the main experimental treatment, categorization, as well as the other experimental treatments. Our primary goal is to see how the presentation of information about investments affects subject investment decisions.

We begin in Section 2.1 by discussing the portfolio allocation problem that subjects face. In Section 2.2, we discuss optimal decision making in this context. In Sections 2.3 and 2.4, we discuss the treatments and the logistics of the experiment.

\subsection{Characteristics of Investments}

Subjects in the experiment perform a portfolio allocation task. In each of four trials, each subject is asked to allocate $\$ 12$ among six lotteries, which we will refer to as "investments." Negative allocations are not permitted. In this subsection, we analyze the investment problem that is common to each trial.

Panel A of Figure 1 presents the information about the six investments: the possible high and low returns and summary statistics for each — the average return, the range (high return minus low return), and the ratio of the return to the range, which we call the return/risk ratio. Panel C provides the same information with a slightly altered presentation in which the investments are 
arranged into two groups of three. This is the "categorized" display that we describe below. The return/risk ratio is half the Sharpe ratio. Thus, it reflects the same information as the Sharpe ratio, but is easier to explain to subjects.

Throughout the experiment, subjects at a minimum see the information in Panel A of Figure 1. The ordering in the baseline trial is the same as in Figure 1, but differs in the other trials (see Table A1 in the appendix).

In determining the outcome of a trial, either all investments earn the high return (with probability 0.5 ) or all investments earn the low return. This perfect correlation of investment returns is emphasized in the instructions - subjects have to correctly answer a question about this. Because subjects are always presented with at least the information in Figure 1, they do not need to compute means or standard deviations. Moreover, because the returns are perfectly correlated across investments, subjects need not understand subtleties associated with diversification. ${ }^{3}$

\subsection{Optimal Investment Allocations}

Given the information in Figure 1, what should subjects do? Theory suggests that subjects in experiments with small gambles should behave in a risk-neutral fashion unless they are extraordinarily risk averse [Rabin, 2000]. Nonetheless, subjects in experiments commonly do behave in a risk-averse fashion.

Risk-Neutral Subjects A risk-neutral subject would select B exclusively, as it has the highest average return.

Risk-Averse Subjects The optimal investment choice for a subject exhibiting risk aversion entails choosing investment A, B, or a combination of the two. To understand why, consider Figure 2, which presents two graphical depictions of the investments from Panel A in Figure 1. (Neither

\footnotetext{
${ }^{3}$ This design choice avoids well known difficulties that subjects have in accounting correctly for correlation and diversification in investment portfolio decisions. See, for example, Kroll et al. [1988], Kroll and Levy [1992], and numerous citations to these works.
} 
Figure 1: Displays of Investment Alternatives Used in the Allocation Stages of the Experiment. The information in Panels $\mathrm{A}$ and $\mathrm{C}$ is seen in every trial by every subject in the uncategorized and categorized treatments, respectively. The order in which assets are displayed changes across trials, but A, B, and C are always grouped together, as are D, E, and F. Panels B and D show the star ratings appended to Tables $\mathrm{A}$ and $\mathrm{C}$ in one of the trials.

Panel A: Basic information about the investments in the uncategorized treatment.

\begin{tabular}{|l|l|l|l|l|l|l|l|}
\hline Alternative: & A & B & C & D & E & F \\
\hline High Return: & $130 \%$ & $185 \%$ & $125 \%$ & $200 \%$ & $225 \%$ & $190 \%$ \\
\hline Low Return: & $30 \%$ & $15 \%$ & $-25 \%$ & $-20 \%$ & $-75 \%$ & $-90 \%$ \\
\hline Average Return: & $80 \%$ & $100 \%$ & $50 \%$ & $90 \%$ & $75 \%$ & $50 \%$ \\
\hline Range of Returns: & $100 \%$ & $170 \%$ & $150 \%$ & $220 \%$ & $300 \%$ & $280 \%$ \\
\hline Return/Risk Ratio: & 0.8000 & 0.5882 & 0.3333 & 0.4091 & 0.2500 & 0.1786 \\
\hline
\end{tabular}

Panel B: Star ratings assigned to each investment, presented to subjects in the uncategorized treatment in Trial 2.

\begin{tabular}{|l|l|l|l|l|l|l|l|}
\hline Uncategorized rating: & & $* * *$ & $* * *$ & $* *$ & $* *$ & $*$ & $*$ \\
\hline
\end{tabular}

Panel C: Basic information about the investments in the categorized display.

\begin{tabular}{|l|l|l|l|l|l|l|l|}
\hline & & \multicolumn{3}{|l|}{ Category I } & \multicolumn{3}{|l|}{ Category II } \\
\hline Alternative: & A & B & C & D & E & F \\
\hline High Return: & $130 \%$ & $185 \%$ & $125 \%$ & $200 \%$ & $225 \%$ & $190 \%$ \\
\hline Low Return: & $30 \%$ & $15 \%$ & $-25 \%$ & $-20 \%$ & $-75 \%$ & $-90 \%$ \\
\hline Average Return: & $80 \%$ & $100 \%$ & $50 \%$ & $90 \%$ & $75 \%$ & $50 \%$ \\
\hline Range of Returns: & $100 \%$ & $170 \%$ & $150 \%$ & $220 \%$ & $300 \%$ & $280 \%$ \\
\hline Return/Risk Ratio: & 0.8000 & 0.5882 & 0.3333 & 0.4091 & 0.2500 & 0.1786 \\
\hline
\end{tabular}

Panel D: Star ratings assigned to each investment, presented to subjects in the categorized treatment in Trial 2.

\begin{tabular}{|l|l|l|l|l|l|l|l|l|}
\hline Categorized Rating: & & $* * *$ & $* *$ & $*$ & $* *$ & $* *$ & $*$ \\
\hline
\end{tabular}



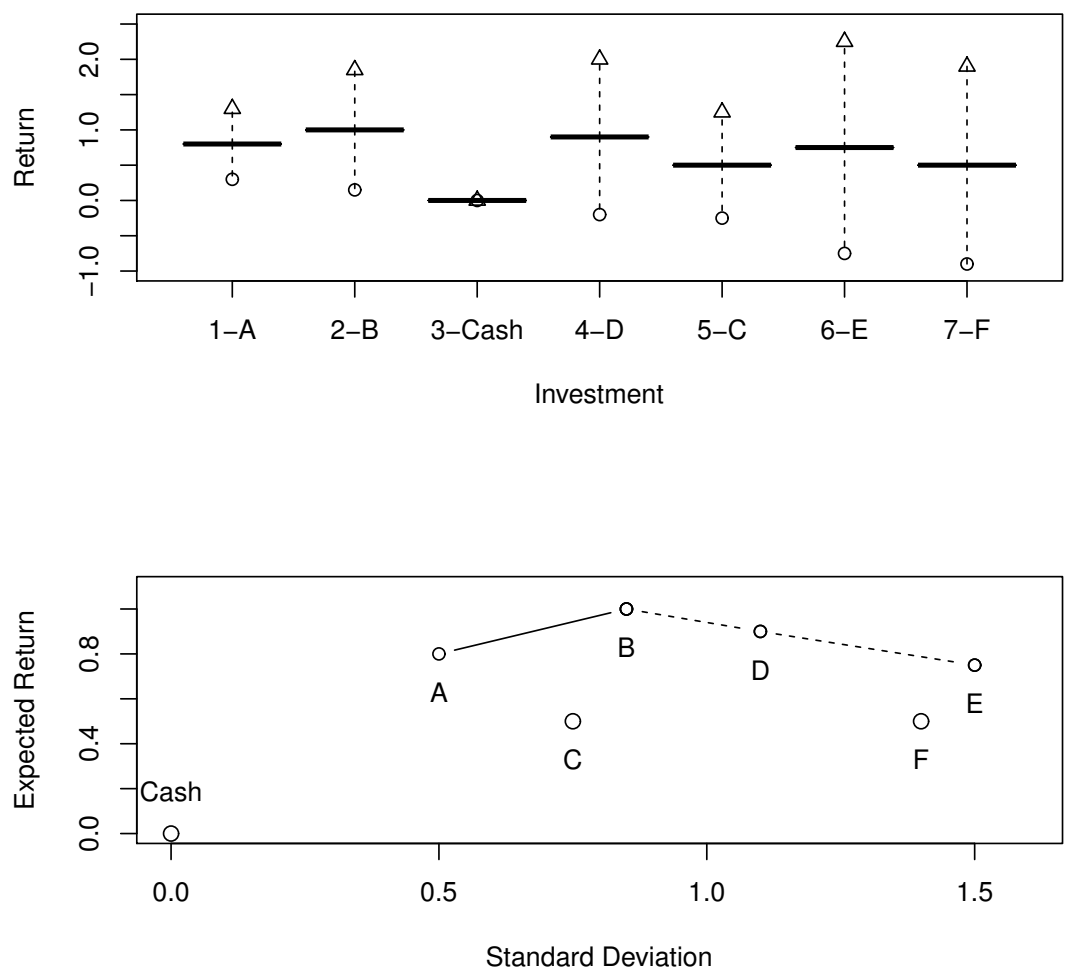

Figure 2: Top panel: Outcomes and mean return for each investment, ordered by minimum return. Investments cash, $\mathrm{C}$, and $\mathrm{F}$ are dominated by $\mathrm{A}$ and $\mathrm{B}, \mathrm{D}$, and $\mathrm{E}$, respectively. Bottom panel: Expected returns and standard deviations of investments along with the efficient frontier for risk averse investors (solid line) and risk seeking investors (dashed line). 
of these figures was presented to the subjects.)

The top panel displays both the high and low returns from Figure 1 and ranks investments by minimum return. We can use this to consider asset choice by a risk-averse subject. It is apparent that cash, C, and F are dominated by the assets to their immediate left in the Figure. The graph also shows why a risk-averse investor strictly prefers B to both D and E. Investments D and E both have lower means than B and a greater range (greater standard deviation). Thus, a risk-averse investor would prefer B by itself to D or E, or to a combination of B with D or E. The comparison of $\mathrm{A}$ and $\mathrm{B}$ is ambiguous, however: $\mathrm{B}$ has a greater mean, a greater range, and the minimum return for $\mathrm{B}$ is below that for $\mathrm{A}$.

The bottom panel of Figure 2 provides a different view of the alternatives, displaying a standard portfolio/efficient frontier graph for the six assets. We can use this to consider a subject with mean-variance utility. The frontier is simple because a single random draw determines whether all investments receive the high return or low return. If a portfolio is invested $1 / 3$ in $\mathrm{A}$ and $2 / 3$ in $\mathrm{B}$, for example, both the mean and standard deviation are $1 / 3$ that of $\mathrm{A}$ plus $2 / 3$ that of $\mathrm{B}$. A portfolio invested in A and D would have a lower mean than one invested in A and B or B and D. Because there is no gain from diversification, efficient portfolios for a subject with mean-variance utility consist of at most two assets.

Risk-Seeking Subjects Some evidence suggests that subjects may be risk seeking across small gambles [e.g., see Berg et al., 2010]. Using the same reasoning as before, a risk seeking investor may hold B, D or E depending on the degree of preference for risk, but not A, C or F. ${ }^{4}$

To summarize, subjects who are not risk-seeking will invest only in some combination of A and B. It is of course possible that, whatever their risk preferences, some subjects will invest suboptimally. In all cases, we will be interested in seeing whether different experimental treatments induce different choices.

\footnotetext{
${ }^{4}$ Further, to achieve any given risk and return combination, a risk seeking subject never needs to hold more than two of $\mathrm{B}, \mathrm{D}$ or $\mathrm{E}$.
} 


\subsection{Categorization and Star Ratings}

Panels $\mathrm{A}$ and $\mathrm{C}$ of Figure 1 present all of the information necessary for subjects to make investment decisions. This information is always visible to participants. The main treatment is categorization, in which the investments are split into two groups. We now discuss the role of categorization and ratings in the experiment.

\subsubsection{Categorization and Display of Investments}

Throughout the experiment, half of the subjects see the non-categorized display in Panel A of Figure 1, and the other half see Panel C, in which the six investments are divided into two groups, labeled "Category I" and "Category II." These categories correspond to investment risk levels: A, $\mathrm{B}$, and $\mathrm{C}$ have a smaller range of returns than D, E, and F. Categorized information is displayed with a blank column separating the two groups of three investments. The ordering of investments changes, but the categorization grouping is always the same, based on the variability of returns, with $\mathrm{A}, \mathrm{B}$, and $\mathrm{C}$ always together in one category and $\mathrm{D}, \mathrm{E}$, and $\mathrm{F}$ in the other.

Note that Category I contains the lowest-risk assets, including A and B, and Category II contains the high-risk assets. The categories thus bear a stylized resemblance to different Morningstar asset categories. Subjects were told that investments were categorized using "a commonly used financial method."

\subsubsection{Star Ratings}

In two of the trials, asset ratings are added to the display. Investments have ratings ranging from one star (worst) to three stars (best). The ratings use the ratio of the expected return over the risk (high minus low return), which is proportional to the Sharpe ratio. Subjects are shown star ratings in one trial and are required to assign star ratings in a different trial. In both cases we impose a uniform distribution of stars within a category (if categorized) or across the six investments (if uncategorized). Panels B and D of Figure 1 show the investment ratings based on return/risk ratios 
for categorized and uncategorized treatments.

The critical aspect of categorization is that it changes the way investments are ranked. Without categorization, all investments are ranked as a single group, with A and B both receiving three stars and $\mathrm{E}$ and $\mathrm{F}$ one star. With categorization, investments are ranked within a group. Investment $\mathrm{A}$ has the highest Sharpe ratio and has a 3-star rating whether categorized or not. Investment $\mathrm{F}$ has the lowest Sharpe ratio and is ranked 1-star either way. Categorization, however, drops B from 3 stars to 2 stars and C from 2 stars to 1 star. It raises D from 2 stars to 3 stars and E from 1 star to 2 stars. Our primary question is whether these rating changes affect decisions even though all of the fundamental information remains constant and is displayed throughout the trials.

We base star ratings on the return/risk ratio for several reasons. The return/risk ratio is a simple intuitive criterion that provides a ranking (in the non-categorized treatment) that is roughly consistent with optimal choices for a risk-averse investor: A and B receive the highest ratings. Conditional on categorization, the ranking is also correct for both categories: A and B are preferred to $\mathrm{C}$, and $\mathrm{D}$ is preferred to $\mathrm{E}$ and F. Finally, a subject who has studied finance might believe they should perform this kind of calculation; the presentation is intended to reduce computational load for subjects by computing what they might want to compute. ${ }^{5}$

\subsection{Description of the Experiment}

The 266 subjects came from a volunteer pool of undergraduate and MBA students in University of Iowa business classes. Subjects were asked to participate in an on-line experimental session that would last less than an hour. Those agreeing to participate received the web address for the study, a login ID, and a random password. They could participate at their convenience. After logging in, they went through an on-line version of the instructions and exercises given in the Appendix. Those completing the experiment received a $\$ 5$ participation fee and additional payments that depended

\footnotetext{
${ }^{5}$ There are caveats to our use of the return/risk ratio. While it mirrors a common evaluation metric (the Sharpe Ratio), it is generally appropriate for comparing diversified portfolios, not individual assets. Its use assumes specific return distributions and utility functions. It does not identify dominated assets (C for example is dominated by $\mathrm{B}$, but not by E, compared to which it has a higher return/risk ratio).
} 
Figure 3: Initial Investment Alternative

\begin{tabular}{|l|l|}
\hline Alternative: & A \\
\hline High Return: & $100 \%$ \\
\hline Low Return: & $-100 \%$ \\
\hline Average Return: & $0 \%$ \\
\hline Range of Returns: & $200 \%$ \\
\hline Return/Risk Ratio: & 0.0000 \\
\hline
\end{tabular}

on the investment allocation decisions described above.

\subsubsection{Preliminary Section}

Subjects first received instructions and general information about the experiment. They were shown a sample table for one asset that mimicked the presentation in the experiment.

Second, subjects completed a three-question quiz on the determination of payments in the experiment. The three questions were intended to insure that subjects understood how to compute the return they would receive in the high and low states (two questions), and that returns on all assets were perfectly correlated (one question). Subjects could not proceed until they answered all questions correctly.

Finally, to measure their willingness to gamble, subjects chose whether to allocate $\$ 1$ to a single, actuarially fair investment alternative. Figure 3 shows how this was presented to subjects. ${ }^{6}$

\subsubsection{Trials}

The main portion of the experiment consists of four trials:

- Initial baseline trial: Subjects see the basic information about the investments and allocate $\$ 12$.

\footnotetext{
${ }^{6}$ We chose this procedure because elicited risk references are not necessarily stable across institutions (see for example, Berg et al. [2005]). The task here, its presentation and the choice procedure is essentially identical to tasks, presentations and procedures used in in the main experimental trials.
} 
- Rated trial: Subjects are shown star ratings for the investments together with the basic information about the investments, and allocate $\$ 12$.

- Self-rated trial: Subjects see the basic information and are required to assign star ratings to the investments. They then allocate $\$ 12$.

- Final baseline trial: Subjects see the basic information about the investments and allocate $\$ 12$.

Table 1 summarizes the structure of the different treatments. Half of the subjects experience trials in the order shown. Subjects are shown star ratings for the investments in the second trial (the "rated" trial), and rank the investments themselves in the third trial (the "self-rated" trial). This order is reversed for half of the subjects. They see the self-rated trial first and the rated trial second. All of the subjects see a baseline display in the first and fourth trials. Subjects in the categorized treatment see a categorized display in all four trials. Our main interest is the effect of categorization.

Treatments include grouping the investment information in different ways (categorization), telling subjects in Trials 2 and 3 the rule used in assigning stars (the rating rule treatment), and reversing the order of the 2 nd and 3rd trials (the order treatment). The three treatmentscategorization, rating rule, and order - result in a $2 \times 2 \times 2$ design with 8 treatment combinations. Each treatment combination was thus presented to $1 / 8$ of the subjects.

The ordering of investments differed across trials, but the grouping of investments did not change: in both categorized and non-categorized treatments, investments A, B, and C (not necessarily in that order) were in either the first three or the last three columns. Investments D, E and F (not necessarily in that order) were in the other three columns. ${ }^{7}$ In uncategorized treatments, there was no mention of categorization.

\footnotetext{
${ }^{7}$ We associate the labels "A" through "F" with specific alternatives here for expositional convenience. Subjects were always shown alternatives labeled "A" through " $\mathrm{F}$ " in order from left to right regardless of the actual investment alternatives that appeared in each column.
} 
Table 1: The entry in each cell reports what subjects see in each trial and treatment. In each trial, subjects allocate $\$ 12$ across the six investments. In the experiment, half of the subjects perform Trial 2 before Trial 3 with the other half reversing the order. In the Rated and Self-rated trials, half of the subjects (the same half in each trial) are told the rule determining ratings.

\begin{tabular}{lllll} 
& & \multicolumn{3}{c}{ Treatment } \\
\cline { 2 - 5 } & Trial & Non-categorized & Categorized & Rating rule \\
\hline 1: & $\begin{array}{l}\text { Initial } \\
\text { Baseline }\end{array}$ & Figure 1, Panel A & Figure 1 Panel C & \\
\hline 2: & Rated & Figure 1, Panels A + B & Figure 1, Panels C + D & $\begin{array}{l}\text { provided to } \\
\text { half of subjects }\end{array}$ \\
\hline 3: & Self-rated & $\begin{array}{l}\text { Figure 1, Panel A, sub- } \\
\text { ject ranks investments }\end{array}$ & $\begin{array}{l}\text { Figure 1, Panel C, sub- } \\
\text { ject ranks investments }\end{array}$ & $\begin{array}{l}\text { provided to } \\
\text { half of subjects }\end{array}$ \\
\hline 4: & Final & Figure 1, Panel A & Figure 1 Panel C & \\
& Baseline & & & \\
\hline
\end{tabular}

\subsubsection{Knowledge, Experience, and Demographics}

After completing the trials, subjects filled out knowledge and demographic surveys, both of which are reproduced in the Appendix. The demographic survey, adapted from Oliven and Rietz [2004], asks about gender, age, marital status, education, etc. The knowledge survey, also adapted from other sources as noted in Appendix B, asks subjects to self-report on their own financial market knowledge and experience (four questions) and asks about simple definitions, basic concepts, applications of concepts to risk and return relationships, and asset allocation (nine questions). Obviously, pre-existing financial knowledge and experience could affect the behavior of subjects. ${ }^{8}$ An example of a question on the experience portion of the survey is "How would you classify your knowledge of financial markets?" with answers ranging from "No knowledge" to "Advanced." Treating the responses as cardinal and summing them, the maximum score is 14 . We scale this to be between 0 and 1. For the knowledge portion of the survey, an example of a question is "Common stocks

\footnotetext{
${ }^{8}$ There is a sizable literature on knowledge and financial decision making. For example, Bernheim et al. [2001] and Bernheim and Garrett [2003] discuss how knowledge affects savings rates. Lusardi and Mitchell [2007] discuss how financial literacy affects retirement planning. Anderson and Settle [1996] show significant effects of prior knowledge on biases in financial decisions. Grinblatt et al. [2011] suggest that higher IQ is associated with greater stock market participation and a higher Sharpe ratio. Finally, Sunden and Surette [1998] suggest that gender may affect asset allocation in defined contribution retirement savings plans.
} 
always provide higher returns than bonds or money market investments." The permitted answers were "True," "False," and "Don't Know." The knowledge score is the number of correct answers, out of 9 .

\subsubsection{Payoffs}

Finally, three random numbers determined payoffs:

1. the payoff to the initial $\$ 1$ investment,

2. which trial's portfolio allocation would be used to determine payment, and

3. whether investments in the selected trial paid the high or low return.

After learning their total payment, the subjects answered a last question about their satisfaction with their own decisions in the experiment.

After completion of the experiment, the University of Iowa mailed checks for the total amounts to the subjects. The maximum possible payment was earned if a participant invested $\$ 1$ in the initial bet and $\$ 12$ in Alternative $\mathrm{E}$ in the randomly-selected trial, and then received the high payoff for both. Including the participation fee, the payoff would be $\$ 5+\$ 1 \times(1+1)+\$ 12 \times(1+2.25)=\$ 46$.

\subsection{Intepretation and Hypotheses}

Before examining the results, we discuss design and interpretative issues.

\subsubsection{Design considerations}

The experimental task is not trivial, so we sought to minimize confounds with factors known to affect subject choices in investment portfolio decisions. First, we eliminated learning and income effects. Each subject's final payoff was determined at the end of the experiment, based on the results from the initial fair bet and the investment return resulting from one randomly-selected 
trial. Results in a given trial are unknown and cannot affect subsequent decisions, and because of random selection, subjects have the same incentive in each trial to make an optimal choice. ${ }^{9}$

Second, as we have discussed, in each trial the return outcomes for the six investments are perfectly correlated. This design avoids well known difficulties that subjects have in accounting correctly for correlation and diversification in investment portfolio decisions. ${ }^{10}$

Finally, it is important to understand that the asset allocation task here differs from one subjects would typically encounter in financial education. A subject who remembered and followed a dictum such as "diversification is beneficial," would make suboptimal decisions in this experiment. Thus, if financial knowledge improves performance in the experiment, it is because the subject understands the task, not because he or she had been taught how to do it.

\subsubsection{Interpretation}

The main question we ask is whether subjects are affected by the categorization treatment. The null hypothesis is that categorized ratings should not affect behavior. Here we discuss three hypotheses about subject behavior that we will use to interpret the results.

Experimenter demand effect The experimenter demand effect occurs when subjects respond to cues in an experiment based on what they interpret as socially appropriate behavior [Zizzo, 2010]. An intepretative problem arises when the experimenter demand perceived by subjects is correlated with the experimental predictions, in which case the cues could drive the results. In our case, a possible experimenter demand effect would be subjects responding to stars by investing more in three star investments, and less in one star investments, independently of the economic characteristics of the investment.

Our design allows us to test for this effect. Subjects see no stars in Trial 1, and they are presented with stars in Trial 2. If present, the experimenter demand effect would result in subjects

\footnotetext{
${ }^{9}$ For a discussion of income effects and ruling them out in experiments, see Kahneman et al. [1990].

${ }^{10}$ See, for example, Kroll et al. [1988], Kroll and Levy [1992], and numerous citations to these works.
} 
investing more heavily in three star investments in Trial 2 than in Trial 1. Specifically, there would be increased investment in asset $\mathrm{A}$ in all treatments, asset $\mathrm{B}$ when non-categorized, and asset $\mathrm{D}$ when categorized. We will see in Section 3 that investments in asset A in all treatments and asset $\mathrm{B}$ in the non-categorized treatment are no different in Trial 2 than in Trial $1 .^{11}$

Cognitive challenges Subjects could be cognitively challenged by the experiment. The experimental task is not simple and it's possible that subjects could use ratings to assist them in decision-making. Again, if this is the case, as with the experimenter demand effect we should see a systematic difference between Trial 1 and Trial 2 related to ratings. The absence of such a difference would be evidence that ratings are not being used in this fashion.

Ratings create cognitive dissonance A third possibility is that subjects face cognitive dissonance when a rating is inconsistent with their prior belief about the asset. The theory of cognitive dissonance [e.g., see Akerlof and Dickens, 1982] implies that subjects will try to harmonize their behavior and belief. In our context, categorized ratings could create dissonance by, for example, reducing the star rating for $\mathrm{B}$, which (as we will see) was a popular investment in Trial 1 . The subject confronted with a low assigned rating can only reconcile behavior and information by reducing investment.

Interestingly, a subject assigning a rating may be less likely to experience dissonance since the subject is in control of both the rating and the investment decision, which affords the opportunity to align the two.

\section{Results}

In this section, we present the results. We first summarize the characteristics of subjects and provide basic data about the experiment. Subjects on average behave reasonably in the first, untreated

\footnotetext{
${ }^{11}$ Even if we were to conclude that results were due to experimenter demand, one could imagine this same effect being present in financial markets, with investors feeling social pressure (from brokers, advisers, and colleagues) to invest in assets with more stars.
} 
trial, investing primarily in $\mathrm{A}$ and $\mathrm{B}$, avoiding the dominated assets, and not diversifying. We then look at performance across trials, examining the effects of treatment, asking whether knowledge mitigates these effects, and exploring different economic explantions for the results. We find that categorized ratings do affect investment and worsen performance, and we find some evidence that forcing subjects to self-rank affects performance. We conclude that the results are unlikely to be explained by the experimenter demand effect or by subjects finding the task too difficult, although there is clearly evidence that some subjects are at times confused. Finally, we look at overall performance across trials and show that categorized subjects in Trial 2 have a lower overall Sharpe ratio, but that this is somewhat reduced for more knowledgable subjects.

\section{$3.1 \quad$ Subjects}

Table 2 provides summary statistics by treatment, including the number of subjects, the gender composition, the Experience Index, Knowledge Score, how much time the subjects spend in the asset allocation portions of the experiment (on average, roughly two minutes per round), and their total payment. Either 33 or 34 subjects participated in each treatment; $39 \%$ were female. The average total payoff was $\$ 28.35$ with a standard deviation of $\$ 10.06$, a maximum of $\$ 44.00$, and a minimum of $\$ 8.50$. According to Kruskal-Wallis rank sum tests, the only significant difference in summary statistics across treatments is in the time spent during allocation. ${ }^{12}$

Women in the study were significantly likelier to take the initial bet (55\% vs $39 \%$ for men, p-value less than 0.01) and had a significantly lower average knowledge score (5.91 vs 6.86) and experience (0.22 vs 0.38$)$. Both differences were significant with a p-value less than $0.0001 .^{13}$

\footnotetext{
${ }^{12}$ While the time spent is highly variable and highly skewed, there are small, but significant differences. The median subject in categorized treatments spent 9 seconds more per decision trial than the median subject in uncategorized treatments (rank sum test p-value $=0.0781$ ); about 14 seconds more per trial with the ranking rule given than without (rank sum test p-value $=0.0163$; and about 17 seconds more per trial when self-ranking preceeds given rankings than vice versa (rank sum test $\mathrm{p}$-value $=0.0242$ ). While interesting, it is expected. Explaining categorization requires more text on the decision page. Ranking according to a given rule, especially within categories, may take more time than ranking according to one's own preferences. Etc.

${ }^{13}$ Table A2 in the Appendix presents correlations for gender, taking the initial bet, experience, and knowledge.
} 
Table 2: Summary information by treatment. The Experience Index is the scaled average response on questions 1-4 on the Knowledge Survey in the Appendix, where the response values for each question are 1 through 4 in the order of the answers. The Knowledge Score is the mean score for answering questions 5-13 in the Knowledge Survey. Seconds Spent in Decision Stages is total time spent selecting allocations for all four stages.*

\begin{tabular}{rrrrrrrrrrr}
\hline & Treatment & 1 & 2 & 3 & 4 & 5 & 6 & 7 & 8 & Overall \\
\hline Categorized? & Yes & Yes & Yes & Yes & No & No & No & No & N/A \\
Rating Rule Given? & No & Yes & No & Yes & No & Yes & No & Yes & N/A \\
Stage II or III First? & II & II & III & III & II & II & III & III & N/A \\
& Obs. & 34 & 34 & 33 & 33 & 33 & 33 & 33 & 33 & 266 \\
& \% Female & $32 \%$ & $35 \%$ & $42 \%$ & $42 \%$ & $33 \%$ & $44 \%$ & $36 \%$ & $44 \%$ & $39 \%$ \\
\% Married & $18 \%$ & $3 \%$ & $9 \%$ & $6 \%$ & $12 \%$ & $6 \%$ & $0 \%$ & $9 \%$ & $8 \%$ \\
Making Initial Bet & $53 \%$ & $50 \%$ & $52 \%$ & $39 \%$ & $45 \%$ & $45 \%$ & $36 \%$ & $42 \%$ & $45 \%$ \\
\hline Experience & Mean & 0.34 & 0.30 & 0.27 & 0.29 & 0.36 & 0.32 & 0.32 & 0.31 & 0.31 \\
Index & Std. Dev. & 0.20 & 0.24 & 0.17 & 0.21 & 0.21 & 0.19 & 0.24 & 0.22 & 0.21 \\
\hline Knowledge & Mean & 6.79 & 6.35 & 6.15 & 6.67 & 6.82 & 6.21 & 6.39 & 6.61 & 6.50 \\
Score & Std. Dev. & 1.84 & 1.52 & 1.91 & 1.49 & 1.40 & 1.91 & 2.05 & 1.48 & 1.71 \\
\hline Seconds & Mean & 563 & 447 & 427 & 608 & 376 & 478 & 399 & 517 & 469 \\
in Decision & Median & 373 & 354 & 431 & 502 & 342 & 380 & 350 & 437 & 384 \\
Stages* & Std. Dev. & 476 & 226 & 130 & 404 & 262 & 302 & 161 & 267 & 292 \\
\hline Total & Mean. & $\$ 27.36$ & $\$ 28.56$ & $\$ 28.04$ & $\$ 28.22$ & $\$ 25.72$ & $\$ 29.99$ & $\$ 28.18$ & $\$ 30.78$ & $\$ 28.35$ \\
Payment & Std. Dev. & $\$ 10.58$ & $\$ 10.70$ & $\$ 10.18$ & $\$ 9.36$ & $\$ 9.95$ & $\$ 9.81$ & $\$ 9.96$ & $\$ 10.12$ & $\$ 10.06$ \\
\hline
\end{tabular}

*Seconds in Decision Stages does not count time reading instructions or answering other questions. This variable was not recorded in the early stages of the experiment, so it is available only for: $18,22,22,23,33,33,33$, and 33 observations in treatments 1 through 8, respectively. We also add medians to this row because, sometimes, this variable is highly skewed. 


\subsection{Investment in Trial 1}

The first question is how subjects performed on the basic allocation task in Trial 1, without treatments. The answer is that subjects invested most heavily in A and B, mostly avoided the dominated assets, and did not naively diversify.

Figure 4 is a violin plot depicting the density function across subjects for investment in Trial 1 , for each asset and cash. The median level of investment is represented in each plot by a white dot, the interquartile range by a heavy black line, and the contours of the enveloping curve depict a kernel density, effectively a rotated histogram. A and B were the only assets for which a significant percentage of subjects invested $\$ 4$ or more, and the mean investment in the two assets combined was $\$ 7.91$. For each of the domninated assets $\mathrm{C}, \mathrm{F}$, and Cash, $75 \%$ or more of subjects invested 0 . Investments in Asset D constituted the bulk of investment in the high-risk group of assets.

We can also ask to what extent subjects diversify, even though there is no value to investing in more than two assets. Figure 5 depicts a violin plot for the cumulative investment across 6 assets in Trial 1, with investments for each subject sorted in order of the amount invested. The figure shows that the median investor has the bulk of their cash - almost $\$ 10$ - invested in two or fewer assets and all of their $\$ 12$ invested in three or fewer assets. $75 \%$ of investors have at least $\$ 10$ in three or fewer assets. A small fraction of investors invests $\$ 12$ across 6 assets and eleven subjects at some point invested in 7 assets. ${ }^{14}$ The figure demonstrates that there is heterogeneity across subjects, but also reinforces the conclusion that the bulk of investors do not naively diversify.

Finally, we checked for spurious correlation between subject behavior and treatments by computing the significance of the correlation between Trial 1 investments and each of the three treatments, none of which are in effect in Trial 1 . None of the correlations were significant at the $5 \%$ level. ${ }^{15}$ 


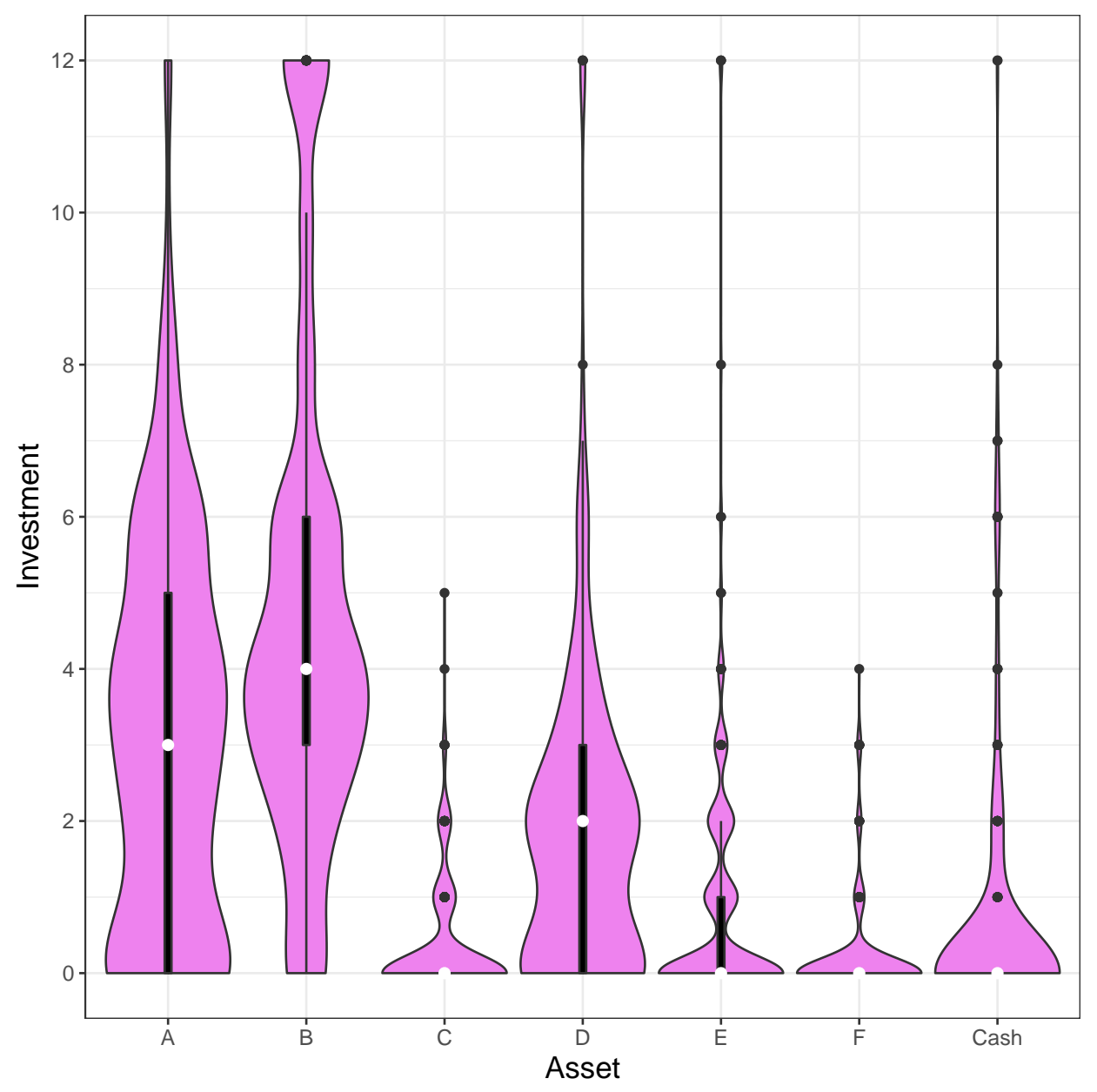

Figure 4: Violin plot depicting investment by asset in Trial 1. The dark line in the center shows the interquartile range, with the median a white dot. Black points indicate outliers. The overall shape is a kernel density plot. 


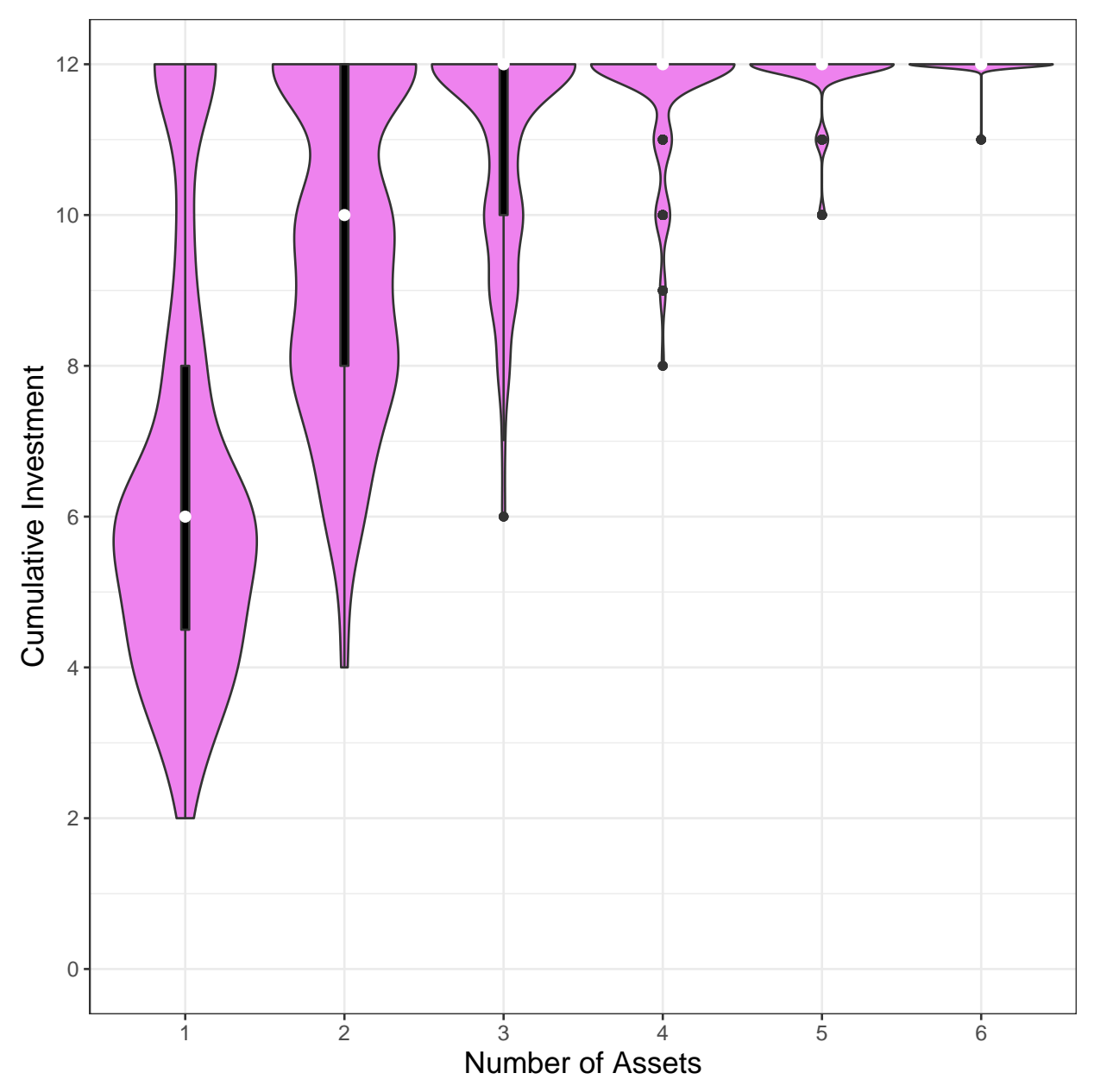

Figure 5: Violin plot depicting the distribution of the number and quantity of assets held by investors in Trial 1. For a given subject, holdings are sorted from greatest to least and cumulated. The plot shows the number of dollars invested in the largest holding, the largest two holdings, etc. 
Table 3: Investment across trials and across the categorization treatment. Initial baseline trial allocations to investments are in Panel A. Panels B and $\mathrm{C}$ display deviations from initial allocations in later trials, in the non-categorized and categorized treatments. Panel D is the difference between Panel $\mathrm{C}$ and Panel B. The first line in each row in Panel B -D is the average deviation and the second is the p-value for the Wilcoxon statistic for differences in the distributions across the stages. ${ }^{* * *},{ }^{* *}$, and ${ }^{*}$ designate significance at the $99 \%, 95 \%$, and $90 \%$ levels of confidence, respectively.

\begin{tabular}{|c|c|c|c|c|c|c|c|}
\hline & A & $\mathrm{B}$ & $\mathrm{C}$ & $\mathrm{D}$ & $\mathrm{E}$ & $\mathrm{F}$ & Cash \\
\hline \multicolumn{8}{|c|}{ Panel A: Average Investment in Trial 1} \\
\hline Mean (\$) & 3.125 & 4.798 & 0.388 & 1.817 & 0.951 & 0.228 & 0.692 \\
\hline Std. Dev. $(\$)$ & 2.648 & 3.336 & 0.797 & 2.078 & 1.759 & 0.666 & 1.818 \\
\hline \multicolumn{8}{|c|}{ Panel B: Changes from Trial 1 in Non-categorized Treatment } \\
\hline \multirow[t]{2}{*}{ Trial 2} & 0.225 & 0.310 & 0.093 & -0.256 & $-0.450^{* * *}$ & -0.016 & 0.093 \\
\hline & 0.446 & 0.143 & 0.297 & 0.155 & 0.001 & 1.000 & 0.425 \\
\hline \multirow[t]{2}{*}{ Trial 3} & 0.426 & -0.248 & 0.062 & -0.302 & $-0.450^{* * *}$ & -0.078 & 0.589 \\
\hline & 0.117 & 0.125 & 0.474 & 0.036 & 0.004 & 0.283 & 0.015 \\
\hline \multirow[t]{3}{*}{ Trial 4} & 0.310 & 0.341 & -0.031 & -0.256 & $-0.372^{* *}$ & 0.000 & 0.008 \\
\hline & 0.427 & 0.173 & 0.676 & 0.180 & 0.018 & 0.331 & 0.430 \\
\hline & \multicolumn{7}{|c|}{ Panel C: Changes from Trial 1 in Categorized Treatment } \\
\hline \multirow[t]{2}{*}{ Trial 2} & 0.418 & $-0.694^{* * *}$ & -0.075 & $0.425^{* *}$ & -0.090 & 0.142 & -0.127 \\
\hline & 0.154 & 0.005 & 0.169 & 0.015 & 0.695 & 0.136 & 0.239 \\
\hline \multirow[t]{2}{*}{ Trial 3} & 0.448 & $-0.985^{* * *}$ & -0.045 & 0.157 & $-0.321^{* *}$ & 0.104 & 0.642 \\
\hline & 0.095 & 0.000 & 0.479 & 0.515 & 0.027 & 0.240 & 0.294 \\
\hline \multirow[t]{2}{*}{ Trial 4} & 0.373 & -0.425 & $-0.164^{* *}$ & 0.119 & 0.037 & 0.104 & -0.045 \\
\hline & 0.336 & 0.132 & 0.014 & 0.592 & 0.604 & 0.234 & 0.270 \\
\hline \multicolumn{8}{|c|}{ Panel D: Difference Between Changes in Categorized and Non-Categorized Treatments } \\
\hline \multirow[t]{2}{*}{ Trial 2} & 0.193 & $-1.004^{* * *}$ & $-0.168^{* *}$ & $0.681^{* * *}$ & $0.360^{* * *}$ & 0.157 & -0.220 \\
\hline & 0.829 & 0.002 & 0.012 & 0.006 & 0.004 & 0.309 & 0.755 \\
\hline \multirow[t]{2}{*}{ Trial 3} & 0.021 & $-0.737^{* *}$ & $-0.107^{*}$ & $0.459^{* *}$ & 0.129 & 0.182 & 0.053 \\
\hline & 0.741 & 0.041 & 0.055 & 0.029 & 0.583 & 0.141 & 0.232 \\
\hline \multirow[t]{2}{*}{ Trial 4} & 0.063 & $-0.766^{* *}$ & $-0.133^{*}$ & 0.375 & $0.409^{* *}$ & 0.104 & -0.053 \\
\hline & 0.942 & 0.049 & 0.073 & 0.125 & 0.038 & 0.205 & 0.121 \\
\hline
\end{tabular}




\subsection{Investment in Trials 2 through 4}

Table 3 summarizes investment levels in the first and subsequent trials, across all subjects and with respect to the categorization treatment. Panels $\mathrm{B}$ and $\mathrm{C}$ shows how investment levels for each asset change for each trial relative to the Baseline, for subjects in the non-categorized (Panel B) and categorized treatment (Panel C). Panel D shows the difference in these changes between the two treatments (i.e., it is a difference in differences).

The main result, in Panel $\mathrm{D}$, is that the change in investment is consistent with the rating change due to categorization. Subjects invest more when the rating is higher (D and E), less when it is lower (B and $\mathrm{C}$ ), and there is no change when the rating is the same across treatments (A and $\mathrm{F})$.

Here is a summary of the results in the table:

- Panel A shows that average investment is greatest in assets A and B (\$7.91 combined in Trial 1) and lowest in the dominated assets, $\mathrm{C}$ and $\mathrm{F}$ (\$0.62 combined in Trial 1). Average investment in Cash in Trial 1 was $\$ 0.69$.

- Panel B shows that, in non-categorized treatments, ratings in Trials 2 and 3 have little effect on investment levels. The exception is E, which receives one star in the non-categorized treatments, and for whcih investment falls significantly. This drop remains when ratings are removed in Trial 4.

- Panel $\mathrm{C}$ shows that categorization reduces investment in B in both Trials 2 and 3 , and to a lesser extent increases investment in D. This pattern is consistent with the categorized star ratings of $\mathrm{B}$ (2 stars) and D (3 stars).

- Panel D shows no categorization/rating interaction effects for A (always rated 3 stars) and F (always rated 1 star). But, in Stage 2, investment levels in B and C are both significantly

\footnotetext{
${ }^{14}$ Of the eleven, three subjects invested in 7 assets three times.

${ }^{15}$ We also computed correlations with treatments against a dummy variable for the investment level being zero. Again, none were significant.
} 
lower when they are rated lower due to categorization. Similarly, investment levels in D and E are significantly higher when they are rated higher due to categorization. This is exactly the effect we hypothesize. The effects on B and C remain when subjects self-rate and when ratings are removed. The effect for D remains when subjects self-rate and for E when ratings are removed.

- Consistent with Figure 5, subjects do not naively diversify: a test for equality of investment across investments A through $\mathrm{F}$ is rejected. ${ }^{16}$ Subjects do not use the $1 / N$ rule [Benartzi and Thaler, 2001].

The results in Table 3 are inconsistent with both the experimenter demand effect and the notion that subject responses are due to cognitive challenges. There is no significant change from Trial 1 to Trial 2 in investment in A, or in B in the non-categorized treatment; this rules out subjects naively investing in accord with stars. The fact that subjects do reduce investment in $\mathrm{B}$ when it is rated two stars suggests that the two star rating is a reduction from the implicit rating they assigned in Trial 1 . We cannot definitively say why subjects reduce investment in B, but cognitive dissonance seems like a possible explanation.

\subsection{Cash Holdings}

Across the 4 trials, 162 subjects never hold cash. An additional 39 subjects have average cash holdings of less than $\$ 1$ per trial. ${ }^{17}$ At the other extreme, one subject in the categorized group holds only cash throughout the experiment and one subject does so twice. The remaining subjects who hold cash at some point do so only once. ${ }^{18}$ Cash-holding peaks in Trial 3, when subjects are asked to provide ratings. Eighteen subjects in this case invest only in cash, with 14 of those in the treatment that did not explain the rating rule. We have no definitive explanation for this behavior,

\footnotetext{
${ }^{16} \mathrm{~A}$ Kruskal-Wallis test rejects equality of means with a p-value of $2.2 \mathrm{e}-16$.

${ }^{17}$ Table A3 shows cash holdings broken down by trial and whether the subject was in the group that was told the rating rule.

${ }^{18} \mathrm{~A}$ probit regression shows that having a higher knowledge score makes it less likely that subjects will invest solely in cash. Other characteristics are not predictive.
} 
but it seems likely that asking subjects to actively engage in analysis created poorer outcomes for a significant subset. ${ }^{19}$

\subsection{Regression Analysis of Investment in All Trials}

We now examine in more detail investment behavior in each asset by running a single regression across all trials and subjects. We would like to understand, for example, determinants of performance in Trial 1, and whether subject knowledge mediates treatment effects in later trials. For each asset, we control for subject characteristics and treatments:

$$
I_{i j k}=\alpha_{i}+\beta_{1} X_{j}+\beta_{2} T_{k=2} X_{2, j}+\beta_{3} T_{k=3} X_{3, j}+\beta_{4} T_{k=4} X_{4, j}+\epsilon_{i, j}
$$

where $X_{j}$ is a vector of subject characteristics and $X_{k, j}$ is a vector of controls specific to each trial. $T_{k=n}$ is a dummy variable that takes the value 1 in Trial $n$. We estimate a censored regression to account for investment amounts being between 0 and $12 .{ }^{20}$ We also cluster standard errors by subject. Because there is effectively no treatment in Trial 1, we control for subject characteristics and, as a placebo, categorization. In trials 2-4, results depend both upon characteristics and treatments. Equation (1) should be viewed as an elaboration upon Table 3.

We find that more knowledgable and experienced subjects behave more rationally in the baseline trial and that taking the initial bet is associated with holding riskier investments. In later trials, subjects are affected by the categorization treatment, they invest in accord with the ratings they assign, and knowledge and experience do not significantly mitigate the effect of treatments.

Explanatory variables, for which summary statistics are provided in Table 4, include:

Knowledge Total correct answers for the nine questions on the knowledge test, normalized to be

\footnotetext{
${ }^{19}$ Subjects responded to a satisfaction survey after each trial and were asked if they wished they could change their decision. None of the 18 subjects investing only in cash in the Self-Rated trial said they wished they could change their decision, and for the 10 who did wish they could change, none invested anything in cash. Ten of the 18 experienced self-rating first, and eight of those were in the treatment not providing the rating rule.

${ }^{20}$ Investments range from $\$ 0$ to $\$ 12$ and are discrete, occurring in one dollar increments. As a robustness check, we also estimated ordered probit models and got essentially identical results. We present the censored regression models because they are easier to interpret.
} 
Table 4: Summary statistics for regression variables. "Female" is a dummy variable where males are 0, females are 1; "Experience" and "Knowledge" are both based on a survey response scaled from 0 to 1 and normalized to have mean 0; "RiskBet" is a dummy variable for taking the initial risky bet; "Cat" and "Rule" are dummy variables for being in the treatments that are categorized and told the rating rule; and "Selfrank A - F" are the stars assigned by subjects minus the number of stars those assets have in the non-categorized treatment.

\begin{tabular}{rrrrr}
\hline & Mean & Std Dev & Min & Max \\
\hline Female & 0.384 & 0.487 & 0.000 & 1.000 \\
Experience & 0.000 & 0.210 & -0.315 & 0.685 \\
Knowledge & -0.000 & 0.190 & -0.722 & 0.278 \\
RiskBet & 0.456 & 0.498 & 0.000 & 1.000 \\
Cat & 0.510 & 0.500 & 0.000 & 1.000 \\
Rule & 0.494 & 0.500 & 0.000 & 1.000 \\
Selfrank A & -0.365 & 0.638 & -2.000 & 0.000 \\
Selfrank B & -0.430 & 0.560 & -2.000 & 0.000 \\
Selfrank C & -0.452 & 0.633 & -1.000 & 1.000 \\
Selfrank D & 0.407 & 0.621 & -1.000 & 1.000 \\
Selfrank E & 0.650 & 0.551 & 0.000 & 2.000 \\
Selfrank F & 0.190 & 0.560 & 0.000 & 2.000 \\
\hline
\end{tabular}

between 0 and 1 , less the mean across all subjects.

Experience Experience index, normalized to be between 0 and 1, less the mean across all subjects.

Gender Dummy variable, female equals one.

RiskBet Dummy variable for taking the initial bet.

Cat Dummy variable for the treatment with categorization.

Rule Dummy variable for the treatment in which the subject is told the rating rule.

SelfRank Rating assigned by the subject in the third trial for a given asset, less the uncategorized rating (Panel B in Figure 1).

Note that we have a choice in equation (1) about specifying subject characteristics. We can either allow their effect to vary individually in each trial or include them in the regression without conditioning on the individual trials. We include them without conditioning, so they are interpreted 
as providing the baseline across all trials. In some cases we interact characteristics with treatment dummies to see if knowledge (for example) alters the effect of the treatment. We discuss trialspecific effects of characteristics where relevant.

We present results separately pertaining to each trial rather than presenting the entire regression in one table. Two points relating to statistical significance are worth noting. First, because of the large number of coefficients in the regressions, we expect to see some significant coefficients at lesser significance levels as a result of random variation. We try not to over-interpret these cases. Second, across trials, more than $75 \%$ of subjects invest zero in assets C and F. Asset E also has significant zero investment. This is rational, but it means that the regression in those cases loads on the the small number of subjects who do invest. Idiosyncratic behavior may be overweighted. We report results for all assets, but focus our attention on A, B, and D.

\subsubsection{Effects of Subject Characteristics in Trial 1}

Table 5 presents those regression coefficients in equation (1) which are not multiplied by a dummy for Trials 2 through 4 . These coefficients are thus approximately the unconditional effect of characteristics, with one placebo variable, a dummy for the effect of categorization in Trial 1 . The coefficients in all cases are computed conditional on the observation not being censored.

The general conclusion from Table 5 is that subjects responded to the economic characteristics of the investments, and departed in ways consistent with the personal characteristics including knowledge and experience. Investments $\mathrm{A}, \mathrm{B}$, and $\mathrm{D}$ have significant positive intercepts. The other assets have significant negative intercepts. The censored regression allows the independent variables to explain the non-censored variation in subject holdings. ${ }^{21}$ Subjects who took the initial bet invested $\$ 1.22$ more in the highest risk asset, $\mathrm{E}$, more in $\mathrm{F}$, and $\$ 1.25$ less in asset $\mathrm{B}$. A higher knowledge score is associated with increased investment in B and reduced investment in C, E, and F. Specifically, one additional correct question on the knowledge test was associated with a

\footnotetext{
${ }^{21}$ Because the regressions are censored, coefficients need not sum to zero across the assets, and the intercepts do not sum to 12 as they would with simple OLS.
} 
Table 5: Unconditional regression coefficients for Equation (1) for subject characteristics. The explanatory variables are a gender dummy, where 1 denotes female (Gender); a dummy for having taken the initial bet (RiskBet); a dummy for the subject being in the categorized treatment (Cat); the knowledge score normalized to have a mean of 0 (Knowledge); and the Experience score, normalized to 0 (Experience). Responses were left-censored at 0 and right-censored at 12. Standard errors (in parentheses) are clustered by subject.

\begin{tabular}{lcccccc}
\hline & $\mathrm{A}$ & $\mathrm{B}$ & $\mathrm{C}$ & $\mathrm{D}$ & $\mathrm{E}$ & $\mathrm{F}$ \\
\hline Intercept & $2.36^{* * *}$ & $5.50^{* * *}$ & $-1.94^{* * *}$ & $1.21^{* * *}$ & $-1.00^{* *}$ & $-3.83^{* * *}$ \\
& $(0.39)$ & $(0.43)$ & $(0.38)$ & $(0.33)$ & $(0.46)$ & $(0.68)$ \\
T1*Cat & 0.21 & 0.13 & -0.21 & -0.30 & $-0.79^{*}$ & $-1.18^{*}$ \\
& $(0.45)$ & $(0.49)$ & $(0.38)$ & $(0.40)$ & $(0.46)$ & $(0.62)$ \\
Female & 0.53 & -0.26 & $0.63^{*}$ & -0.30 & -0.10 & 0.34 \\
& $(0.39)$ & $(0.44)$ & $(0.34)$ & $(0.33)$ & $(0.42)$ & $(0.56)$ \\
Experience & -0.08 & 2.15 & -0.66 & -0.72 & $-2.56^{*}$ & $-2.34^{*}$ \\
& $(1.15)$ & $(1.37)$ & $(0.90)$ & $(0.96)$ & $(1.32)$ & $(1.33)$ \\
Knowledge & -0.43 & $4.47^{* * *}$ & $-1.55^{*}$ & $-1.58^{*}$ & $-1.91^{*}$ & -1.28 \\
& $(1.08)$ & $(1.44)$ & $(0.93)$ & $(0.92)$ & $(1.06)$ & $(1.43)$ \\
RiskBet & -0.18 & $-1.38^{* * *}$ & 0.26 & 0.43 & $1.25^{* * *}$ & $1.19^{* *}$ \\
& $(0.40)$ & $(0.45)$ & $(0.35)$ & $(0.33)$ & $(0.47)$ & $(0.53)$ \\
\hline Num. obs. & 1052 & 1052 & 1052 & 1052 & 1052 & 1052 \\
Trial 1: & & & & & & \\
Left-censored & 67 & 21 & 199 & 91 & 157 & 228 \\
Uncensored & 192 & 213 & 64 & 168 & 103 & 35 \\
Right-censored & 4 & 29 & 0 & 4 & 3 & 0 \\
All trials: & & & & & & \\
Left-censored & 247 & 135 & 820 & 394 & 697 & 906 \\
Uncensored & 771 & 800 & 232 & 648 & 349 & 145 \\
Right-censored & 34 & 117 & 0 & 10 & 6 & 1 \\
\hline
\end{tabular}


$\$ 0.50(=4.47 / 9)$ increased investment in B. For all but asset A, knowledge and the risky bet had offsetting signs. ${ }^{22}$ Finally, subjects with more investment experience invested less in E and F. The coefficient can be interpreted as the effect of going from no experience to maximum experience.

Women invested more in $\mathrm{C}$, but otherwise, gender effects were not evident. As a placebo test, we included a dummy for the subject being in the categorized treatment. This dummy has significance at the $10 \%$ level for $\mathrm{E}$ and $\mathrm{F}$.

\subsection{The Effect of Star Ratings in Trials 2 and 3}

The second and third trials exposed subjects to star ratings. Two aspects of these trials are especially important. First, in Trial 2, where subjects are shown ratings, the question is whether knowledge mediates the effect shown in Table 3. Second, in Trial 3, in which subjects assign star ratings to the investments, we impose the constraint that they assign equal numbers of one, two, and three star ratings, either within categories or not, depending on the treatment. The question is whether this active participation affects investment decisions.

\subsubsection{Trial 2}

Table 6 shows the coefficients from regression equation 1 for the trial in which subjects are given ratings, with half of the subjects told how the assets are rated. There are three important results in the table.

First, categorization affects investment decisions. Subjects exposed to categorization reduce investment in assets B and $\mathrm{C}$ - both of which have one less star when categorized - by over $\$ 1$ each. To interpret this finding, recall from Table 3 that initial investment was greatest for B, A, and $\mathrm{D}$, in that order, with average investment less than $\$ 1$ for $\mathrm{C}, \mathrm{E}$, and F. We would expect an effect in B if anywhere, and the $\$ 1$ decline in B is economically significant. There is no comparable

\footnotetext{
${ }^{22}$ We also estimated this regression using question 7 , queston 13 , and the sum from the remaining knowledge score questions. Those correctly calculating the return in question 7 invested more in asset B and less in assets D and Cash. A higher score on the remaining knowledge questions were associated with more investment in B and less in $\mathrm{C}$ and Cash.
} 
effect for $\mathrm{A}$ and $\mathrm{F}$, for which the rating is not affected by categorization. There is also no effect on $\mathrm{D}$, for which the rating is increased by categorization.

Second, financial knowledge does not alter the effect of the categorization treatment. Knowledge is interacted with the Trial 2 dummy individually and interacted with the category and rating rule treatment dummies. While more knowledgeable investors in the first trial invest more in B, knowledge does not mediate the effect of categorization. This remains true when performing F-tests on sums of coefficients). ${ }^{23,24}$

Third, there is no strong effect associated with subjects being told the rating rule. The only significant effect, with an F-test taking account of all interactions, occurs with Asset C; being given the rating rule leads to $\$ 1$ less investment for subjects with one additional knowledge score point in the uncategorized treatment (t-statistic of -1.88 ), and $\$ 2.53$ less in the categorized treatment (t-statistic of -3.45).

Finally, the Trial 2 dummy variable is insignificant for all but asset E. As in our discussion of Table 3, we view this as inconsistent with the experimenter demand effect and with cognitivelychallenged subjects using ratings to help make decisions.

\subsubsection{Trial 3}

Subjects are asked to provide their own ratings while choosing investment amounts. This raises two questions:

1. Did subjects assign reasonable ratings?

2. Did subjects invest in accord with the ratings they assigned?

If subjects invest in accord with their ratings, then we should generally see higher ratings correspond with more investment. Subjects in the categorized treatment, however, may be forced

\footnotetext{
${ }^{23}$ Regressions using the individual knowledge score components, not reported, show subjects displaying computation ability investing more in B and less in E, F, and cash, but importantly, knowledge still does not mitigate the effects of categorization.

${ }^{24} \mathrm{~A}$ chi-squared test showed no additional explanatory power from adding a dummy for the rating rule interacted with categorization and knowledge.
} 
Table 6: Regression coefficients for Equation (1) pertaining to Trial 2, denoted by the dummy variable T2. The intercept from Table 5 is duplicated for reference. The explanatory variables for trial 2 are a dummy for being in the categorization treatment (Cat); a dummy for being in the treatment where the rating rule is provided (Rule); and the knowledge score normalized to have a mean of 0 (Knowledge). Responses were left-censored at 0 and right-censored at 12. Standard errors (in parentheses) are clustered by subject.

\begin{tabular}{lcccccc}
\hline & $\mathrm{A}$ & $\mathrm{B}$ & $\mathrm{C}$ & $\mathrm{D}$ & $\mathrm{E}$ & $\mathrm{F}$ \\
\hline Intercept & $2.36^{* * *}$ & $5.50^{* * *}$ & $-1.94^{* * *}$ & $1.21^{* * *}$ & $-1.00^{* *}$ & $-3.83^{* * *}$ \\
& $(0.39)$ & $(0.43)$ & $(0.38)$ & $(0.33)$ & $(0.46)$ & $(0.68)$ \\
$\mathrm{T} 2$ & 0.22 & 0.36 & 0.51 & -0.49 & $-1.39^{* * *}$ & -0.02 \\
& $(0.35)$ & $(0.38)$ & $(0.32)$ & $(0.34)$ & $(0.47)$ & $(0.44)$ \\
T2*Cat & 0.62 & $-1.09^{* *}$ & $-1.21^{* * *}$ & 0.63 & 0.28 & -0.48 \\
& $(0.46)$ & $(0.55)$ & $(0.44)$ & $(0.39)$ & $(0.47)$ & $(0.63)$ \\
T2*Rule & 0.05 & -0.04 & -0.64 & 0.08 & 0.40 & -0.40 \\
& $(0.46)$ & $(0.54)$ & $(0.45)$ & $(0.39)$ & $(0.49)$ & $(0.63)$ \\
T2*Cat*Knowledge & 2.92 & -0.75 & -2.57 & $-3.26^{* *}$ & 0.91 & -2.24 \\
& $(2.09)$ & $(2.31)$ & $(1.79)$ & $(1.59)$ & $(1.68)$ & $(2.80)$ \\
T2*Rule*Knowledge & -0.73 & -0.72 & $-3.41^{*}$ & 0.93 & 2.44 & -3.41 \\
& $(1.95)$ & $(2.12)$ & $(1.79)$ & $(1.60)$ & $(1.92)$ & $(2.51)$ \\
\hline Num. Obs. (trial) & 263 & 263 & 263 & 263 & 263 & 263 \\
Left-censored & 56 & 30 & 205 & 98 & 176 & 225 \\
Uncensored & 200 & 202 & 58 & 163 & 86 & 38 \\
Right-censored & 7 & 31 & 0 & 2 & 1 & 0 \\
\hline
\end{tabular}

${ }^{* * *} p<0.01,{ }^{* *} p<0.05,{ }^{*} p<0.1$ 
to assign a rating which conflicts with their investment (rating B at 2 stars). We find that selfassigned ratings are strongly associated with investment behavior, except when we force a conflict. Forcing a low rating, in other words, does not affect the investment.

Because most investment is in A and B, we initially focus the discussion on those assets.

Subject ratings Subjects assign ratings that generally correspond with those in Table 1, but which also are affected by treatments in an unsurprising way. ${ }^{25}$ For example, subjects consistently rated A highly except in the categorized treatment when not told the rule used to construct the ratings. In this case they roughly split 50-50 between giving the top rating to A and B. ${ }^{26}$ As expected, categorization reduces the correspondence between subject-assigned rating and the objective rating. Overall, when given the rating rule, between $80 \%$ and $90 \%$ of subjects ranked the assets in accord with the rule based on the ratio of return to risk. ${ }^{27}$

Table 7 reports the results of a regression analysis of the self-ratings. The table shows that categorization has a large effect on ratings, reducing the ratings assigned to $\mathrm{B}$ and $\mathrm{C}$ and increasing the rating assigned to $\mathrm{D}$ and E. Categorization also reduced the rating for $\mathrm{A}$, presumably because subjects wished to rate B more highly. Knowing the rating rule has a small effect; non-categorized subjects told the rating rule, for example, gave a higher rating to $\mathrm{C}$ and a lower rating to $\mathrm{E}$, in accord with their Sharpe ratio. Knowledge and experience, however, do not affect the self-rating. On the whole, subjects rate investments reasonably, subject to the restrictions we impose. It is interesting to note that RiskBet and knowledge have no effect on how subjects do the ranking, but as shown in Table 5 these variables do affect investment behavior.

\footnotetext{
${ }^{25}$ Table A4 in the Appendix shows the percentage of subjects assigning each rating in each of four treatments (categorization by the rank rule).

${ }^{26}$ Panel A also implicitly suggests that some subjects were confused about ranks, and gave A a 1 and $\mathrm{C}$ a 3.

${ }^{27}$ As another way to assess subject ratings, we can compute correlations between subject and "correct" ratings across different treatments. The correlation was 0.82 for the uncategorized and 0.67 for the categorized treatment, and 0.71 without the rating rule and 0.78 with the rating rule. The lowest correlation was 0.65 in the categorized treatment without the rating rule, and the highest was 0.87 in the uncategorized treatment with the rating rule.
} 
Table 7: OLS regressions explaining subject-assigned rank in Trial 3. The dependent variable is the subject-assigned rank. The explanatory variables are a gender dummy, where 1 denotes female (Female); a dummy for having taken the initial bet (RiskBet); a dummy for the subject being in the categorized treatment (Cat); a dummy for the subject receiving the rating rule (Rule), and variables denoting the knowledge score normalized to zero (Knowledge) and the experience score normalized to zero (Experience). Standard errors are in parentheses.

\begin{tabular}{lcccccc}
\hline & $\mathrm{A}$ & $\mathrm{B}$ & $\mathrm{C}$ & $\mathrm{D}$ & $\mathrm{E}$ & $\mathrm{F}$ \\
\hline Intercept & $2.78^{* * *}$ & $2.89^{* * *}$ & $1.63^{* * *}$ & $2.16^{* * *}$ & $1.43^{* * *}$ & $1.12^{* * *}$ \\
& $(0.11)$ & $(0.08)$ & $(0.10)$ & $(0.10)$ & $(0.08)$ & $(0.10)$ \\
Female & -0.08 & 0.02 & 0.02 & -0.03 & -0.02 & 0.09 \\
& $(0.08)$ & $(0.06)$ & $(0.08)$ & $(0.07)$ & $(0.06)$ & $(0.08)$ \\
Experience & 0.07 & 0.19 & 0.00 & -0.02 & -0.07 & -0.18 \\
& $(0.20)$ & $(0.15)$ & $(0.19)$ & $(0.17)$ & $(0.15)$ & $(0.19)$ \\
RiskBet & -0.06 & $-0.13^{* *}$ & $0.16^{* *}$ & $-0.13^{* *}$ & 0.07 & 0.09 \\
& $(0.08)$ & $(0.06)$ & $(0.07)$ & $(0.06)$ & $(0.05)$ & $(0.07)$ \\
Cat & $-0.44^{* * *}$ & $-0.46^{* * *}$ & $-0.45^{* * *}$ & $0.75^{* * *}$ & $0.53^{* * *}$ & 0.07 \\
& $(0.10)$ & $(0.08)$ & $(0.10)$ & $(0.09)$ & $(0.07)$ & $(0.10)$ \\
Rule & 0.15 & -0.01 & $0.23^{* *}$ & -0.10 & $-0.26^{* * *}$ & -0.01 \\
& $(0.11)$ & $(0.08)$ & $(0.10)$ & $(0.09)$ & $(0.08)$ & $(0.10)$ \\
Knowledge & 0.07 & 0.07 & 0.40 & -0.07 & -0.21 & -0.26 \\
& $(0.36)$ & $(0.26)$ & $(0.33)$ & $(0.30)$ & $(0.25)$ & $(0.33)$ \\
Cat*Rule & 0.21 & $-0.35^{* * *}$ & -0.22 & -0.04 & $0.30^{* * *}$ & 0.10 \\
& $(0.15)$ & $(0.11)$ & $(0.14)$ & $(0.12)$ & $(0.11)$ & $(0.14)$ \\
Cat*Knowledge & 0.09 & 0.14 & $-0.83^{* *}$ & 0.35 & $0.62^{* *}$ & -0.36 \\
& $(0.39)$ & $(0.29)$ & $(0.36)$ & $(0.33)$ & $(0.28)$ & $(0.36)$ \\
RiskBet*Knowledge & 0.49 & -0.11 & -0.60 & 0.24 & -0.20 & 0.17 \\
& $(0.40)$ & $(0.30)$ & $(0.37)$ & $(0.34)$ & $(0.29)$ & $(0.37)$ \\
\hline $\mathrm{R}^{2}$ & 0.15 & 0.41 & 0.27 & 0.37 & 0.43 & 0.07 \\
Adj. R ${ }^{2}$ & 0.12 & 0.39 & 0.24 & 0.35 & 0.41 & 0.04 \\
Num. obs. & 263 & 263 & 263 & 263 & 263 & 263 \\
RMSE & 0.60 & 0.44 & 0.55 & 0.50 & 0.43 & 0.55 \\
\hline$* * *<0 . *^{* *}<0.05 * * 0$ & & & & &
\end{tabular}


Table 8: Regression coefficients for Equation (1) pertaining to Trial 3. The intercept from Table 5 is duplicated for reference. The explanatory variables are a Trial Dummy (T3), the rank the subject assigned the asset in the trial, a dummy for the subject being in the categorized treatment; and a dummy for the subject being in the treatment where the rank rule is given. Responses were left-censored at 0 and right-censored at 12. Standard errors (in parentheses) are clustered by subject.

\begin{tabular}{lcccccc}
\hline & $\mathrm{A}$ & $\mathrm{B}$ & $\mathrm{C}$ & $\mathrm{D}$ & $\mathrm{E}$ & $\mathrm{F}$ \\
\hline Intercept & $2.36^{* * *}$ & $5.50^{* * *}$ & $-1.94^{* * *}$ & $1.21^{* * *}$ & $-1.00^{* *}$ & $-3.83^{* * *}$ \\
& $(0.39)$ & $(0.43)$ & $(0.38)$ & $(0.33)$ & $(0.46)$ & $(0.68)$ \\
T3 & 0.55 & -0.26 & 0.65 & -0.56 & $-2.65^{* * *}$ & -0.93 \\
& $(0.51)$ & $(0.52)$ & $(0.43)$ & $(0.41)$ & $(0.76)$ & $(0.64)$ \\
T3*SelfRank & $2.07^{* * *}$ & $4.30^{* *}$ & $1.57^{* *}$ & $2.35^{*}$ & $2.33^{* * *}$ & 1.21 \\
& $(0.76)$ & $(1.77)$ & $(0.79)$ & $(1.25)$ & $(0.77)$ & $(1.32)$ \\
T3*Cat & $1.61^{*}$ & -0.65 & 0.00 & -0.35 & $2.39^{* *}$ & -1.47 \\
& $(0.87)$ & $(1.11)$ & $(0.63)$ & $(0.79)$ & $(1.20)$ & $(1.14)$ \\
T3*Rule & 0.58 & 0.06 & -0.44 & -0.05 & $1.63^{* *}$ & 0.85 \\
& $(0.70)$ & $(0.73)$ & $(0.53)$ & $(0.53)$ & $(0.82)$ & $(0.84)$ \\
T3*Cat*Rule & -0.80 & -1.31 & -0.74 & $2.03^{* *}$ & -3.47 & 0.81 \\
& $(1.15)$ & $(1.80)$ & $(0.86)$ & $(0.93)$ & $(2.23)$ & $(1.49)$ \\
T3*SelfRank*Cat & 1.03 & $-3.64^{*}$ & 0.66 & -1.97 & $-3.93^{* * *}$ & $2.59^{*}$ \\
& $(1.14)$ & $(2.03)$ & $(0.97)$ & $(1.43)$ & $(1.35)$ & $(1.36)$ \\
T3*SelfRank*Rule & -0.93 & -3.04 & -1.78 & 0.04 & $-2.69^{* *}$ & -1.13 \\
& $(0.94)$ & $(2.05)$ & $(1.16)$ & $(2.72)$ & $(1.13)$ & $(1.70)$ \\
T3*SelfRank*Cat*Rule & -1.09 & 1.44 & 0.02 & -1.66 & $4.81^{* *}$ & $-13.82^{* * *}$ \\
& $(1.36)$ & $(2.59)$ & $(1.37)$ & $(2.83)$ & $(2.39)$ & $(2.08)$ \\
\hline Num. Obs. (trial) & 263 & 263 & 263 & 263 & 263 & 263 \\
Left-censored & 60 & 49 & 203 & 101 & 187 & 228 \\
Uncensored & 192 & 191 & 60 & 160 & 75 & 35 \\
Right-censored & 11 & 23 & 0 & 2 & 1 & 0 \\
\hline
\end{tabular}

${ }^{* * *} p<0.01,{ }^{* *} p<0.05,{ }^{*} p<0.1$ 
Effect of subject ratings on investment Table 8 reports the Trial 3 coefficients from regression equation 1. The new explanatory variable is Selfrank, which is defined as the difference between the rating assigned by the subject and the non-categorized rating. For example, Asset B has a noncategorized rating of 3 , so the self-rating is 0 if the subject assigns $B$ the non-categorized rating of 3 stars, and -1 if a subject assigns it two stars. Selfrank is included as a standalone variable, and interacted with the categorization and rule dummies. The standalone coefficient in the regression shows that subjects not in the categorized treatment (i.e., for whom Cat $=0$ ) invest more in assets to which they assign higher ratings. The magnitude is between $\$ 1.25$ and $\$ 4.31$ per assigned star.

What happens when categorized subjects are encouraged to give two stars to to both B and E? For both assets, the regression shows that the net effect of the self-ranking variable for categorized subjects is zero (for B) or negative (for E). A subject forced to rate B two stars has a zero net effect of the ranking (the coefficients on the self-rating, and rating/categorization interaction dummy sum to almost exactly zero). For E, a categorized subject not told the ranking rule has a negative effect of the forced higher ranking. It is unforced star ratings that affect investment. Being told the rank rule does not affect this result for most assets. It does seem to matter for E, offsetting the effect of the rating. It is worth noting that Asset E suffers from the small sample problem with only 75 uncensored subjects. Otherwise, there is little evidence that being told the rating rule has any effect on investment. ${ }^{28}$

\subsubsection{Trial 4}

Table 9 reports the coefficients from regression equation 1 for the final trial, which is an untreated repeat of the first. As such, the Trial 4 regression variables measure the effects from subjects having participated in the previous trials. The results are generally not significant. There is a secular

\footnotetext{
${ }^{28}$ In Table 8, note the large negative coefficient for Selfrank for Asset F, for subjects in the categorized treatment who are told the rank rule. Nine subjects gave asset $F$ a rank of three stars and invested 0, instead investing primarily in A, B, and D. These same subjects ranked B and D low, but invested heavily in them. One possible explanation is that these subjects misunderstood the star rating, and the regression coefficient is the result of the regression trying to fit this behavior.
} 
Table 9: Regression coefficients for Equation (1) pertaining to Trial 4. The intercept from Table 5 is duplicated for reference. The explanatory variables are a Trial dummy (T4) and a dummy for the subject being in the categorized treatment. Responses were left-censored at 0 and right-censored at 12. Standard errors (in parentheses) are clustered by subject.

\begin{tabular}{lcccccc}
\hline & $\mathrm{A}$ & $\mathrm{B}$ & $\mathrm{C}$ & $\mathrm{D}$ & $\mathrm{E}$ & $\mathrm{F}$ \\
\hline Intercept & $2.36^{* * *}$ & $5.50^{* * *}$ & $-1.94^{* * *}$ & $1.21^{* * *}$ & $-1.00^{* *}$ & $-3.83^{* * *}$ \\
& $(0.39)$ & $(0.43)$ & $(0.38)$ & $(0.33)$ & $(0.46)$ & $(0.68)$ \\
$\mathrm{T} 4$ & 0.60 & 0.00 & -0.26 & $-0.62^{*}$ & $-1.16^{* *}$ & -0.47 \\
& $(0.42)$ & $(0.45)$ & $(0.36)$ & $(0.35)$ & $(0.47)$ & $(0.50)$ \\
T4*Cat & 0.33 & -0.86 & $-0.90^{* *}$ & 0.22 & 0.23 & -0.53 \\
& $(0.51)$ & $(0.55)$ & $(0.42)$ & $(0.40)$ & $(0.48)$ & $(0.65)$ \\
T4*Knowledge & 0.46 & 0.87 & -1.16 & 1.08 & -1.07 & $-3.24^{* *}$ \\
& $(1.36)$ & $(1.47)$ & $(0.92)$ & $(0.96)$ & $(1.18)$ & $(1.42)$ \\
T4*Gender & -0.55 & 0.48 & 0.38 & 0.41 & 0.17 & 0.89 \\
& $(0.45)$ & $(0.47)$ & $(0.33)$ & $(0.35)$ & $(0.44)$ & $(0.55)$ \\
T4*RiskBet & -0.05 & 0.38 & -0.13 & 0.02 & -0.13 & -0.35 \\
& $(0.40)$ & $(0.44)$ & $(0.32)$ & $(0.33)$ & $(0.40)$ & $(0.50)$ \\
T4* Experience & -0.63 & 1.06 & $1.86^{* *}$ & -0.43 & -1.30 & 0.46 \\
& $(1.17)$ & $(1.34)$ & $(0.84)$ & $(0.85)$ & $(1.03)$ & $(1.08)$ \\
\hline Num. Obs. (trial) & 263 & 263 & 263 & 263 & 263 & 263 \\
Left-censored & 64 & 35 & 213 & 104 & 177 & 225 \\
Uncensored & 187 & 194 & 50 & 157 & 85 & 37 \\
Right-censored & 12 & 34 & 0 & 2 & 1 & 1 \\
\hline${ }^{* * *} p<0.01,{ }^{* *} p<0.05,{ }^{*} p<0.1$ & & & & &
\end{tabular}

decline in investment in $\mathrm{D}$ and $\mathrm{E}$, and more knowledgeable investors sharply reduce investment in F. The coefficients on categorization for B and C are similar to but attenuated from Trial 2 (Table 6), with only that on $\mathrm{C}$ being statistically significant. This is consitent with the result from Table 3 that categorized investors invested less in B and C than non-categorized investors in Trials 2-4, and for D and E the same effect was zero or positive, in line with the star rating shifts due to categorization.

\subsection{Overall Investment Performance}

The primary focus of the preceding analysis has been on investment in individual assets. Table 10 examines overall portfolio performance as measured by the portfolio Sharpe ratio. The analysis 
confirms that categorization harms performance. The table presents regressions explaining the Sharpe ratio and its components in Trial 1, and the difference between the Sharpe ratio in later trials and that in Trial 1.

In Trial 1, more knowledgable investors have a higher expected return and no greater risk, for a higher Sharpe ratio. Those who take the initial bet assume greater risk and an insignificantly lower expected return, which reduces their Sharpe ratio. Gender and experience do not affect overall performance.

In Trial 2, in line with the results in Table 3, categorization reduces performance. More knowledgable subjects are less harmed by categorization, but knowledge overall is statistically insignificant (p-value of 0.138 in an F-test).

The only other statistically significant effect is that those who took the initial bet recoup their performance somewhat in Trials 2 and 4; this may be due to the secular decline in holdings of Asset E evident in Table 3. Interestingly, performance is not recouped in Trial 3.

\section{Related Literature}

This paper is related to several distinct areas of the behavioral literature. Our goal in this section is to provide some overarching context and relate results in the literature to our findings. As discussed in the introduction, we discuss the relation of our findings to work on presentation effects, the effects of financial knowledge, cognitive limitations, and difficulties making portfolio decisions.

\subsection{Presentation Effects}

Subjects have full information about investments. Why would they respond to ratings? There are at least two obvious possibilities. One is that subjects believe the ratings convey additional information. In this case we would expect financial knowledge to mitigate the effect of categorized ratings. There is no significant mitigation from knowledge. Further, we would expect that explaining that ratings are based on the Return/Risk Ratio would mitigate the effect. To the degree that 
Table 10: OLS regressions. For Trial 1 the dependent variables are the expected return, return standard deviation (one-half the range), and the Sharpe ratio (the expected return divided by the standard deviation), for Trials 2 through 4, the depenent variable is the change in the Sharpe ratio from Trial 1. 1 and across trials 2 through 4. An average Sharpe ratio could not be computed for the 22 subjects who in at least one trial invested $\$ 12$ in cash.

\begin{tabular}{|c|c|c|c|c|c|c|}
\hline & \multicolumn{3}{|c|}{ Trial 1} & \multicolumn{3}{|c|}{ Sharpe Ratio, Trials $2-4$} \\
\hline & Exp Ret & Std Dev & Sharpe & $\mathrm{T} 2-\mathrm{T} 1$ & T3 - T1 & $\mathrm{T} 4-\mathrm{T} 1$ \\
\hline \multirow[t]{2}{*}{ Intercept } & $0.858^{* * *}$ & $0.799^{* * *}$ & $1.097^{* * *}$ & 0.028 & 0.033 & 0.045 \\
\hline & $(0.014)$ & $(0.018)$ & $(0.019)$ & $(0.025)$ & $(0.029)$ & $(0.027)$ \\
\hline \multirow[t]{2}{*}{ Female } & $-0.039^{*}$ & -0.042 & 0.006 & 0.009 & 0.021 & -0.036 \\
\hline & $(0.020)$ & $(0.026)$ & $(0.028)$ & $(0.025)$ & $(0.030)$ & $(0.028)$ \\
\hline \multirow[t]{2}{*}{ Experience } & 0.063 & -0.004 & 0.071 & 0.023 & 0.035 & 0.012 \\
\hline & $(0.050)$ & $(0.065)$ & $(0.069)$ & $(0.062)$ & $(0.074)$ & $(0.068)$ \\
\hline \multirow[t]{2}{*}{ Knowledge } & $0.183^{* * *}$ & 0.027 & $0.231^{* * *}$ & -0.058 & -0.165 & 0.070 \\
\hline & $(0.054)$ & $(0.070)$ & $(0.075)$ & $(0.105)$ & $(0.127)$ & $(0.117)$ \\
\hline \multirow[t]{2}{*}{ RiskBet } & -0.029 & $0.052^{* *}$ & $-0.088^{* * *}$ & $0.058^{*}$ & -0.001 & $0.066^{*}$ \\
\hline & $(0.019)$ & $(0.024)$ & $(0.026)$ & $(0.033)$ & $(0.040)$ & $(0.037)$ \\
\hline \multirow[t]{2}{*}{ Cat } & & & & $-0.060^{* *}$ & -0.032 & -0.016 \\
\hline & & & & $(0.030)$ & $(0.036)$ & $(0.034)$ \\
\hline \multirow[t]{2}{*}{ Rule } & & & & -0.009 & 0.029 & -0.011 \\
\hline & & & & $(0.022)$ & $(0.027)$ & $(0.025)$ \\
\hline \multirow[t]{2}{*}{ RiskBet*Cat } & & & & -0.001 & 0.002 & -0.056 \\
\hline & & & & $(0.046)$ & $(0.055)$ & $(0.051)$ \\
\hline \multirow[t]{2}{*}{ Knowledge*Rule } & & & & -0.043 & 0.034 & -0.057 \\
\hline & & & & $(0.119)$ & $(0.145)$ & $(0.134)$ \\
\hline \multirow[t]{2}{*}{ Knowledge*Cat } & & & & $0.223^{*}$ & 0.159 & -0.027 \\
\hline & & & & $(0.119)$ & $(0.146)$ & $(0.134)$ \\
\hline$\overline{\mathrm{R}^{2}}$ & 0.133 & 0.026 & 0.118 & 0.069 & 0.023 & 0.032 \\
\hline Adj. $R^{2}$ & 0.120 & 0.011 & 0.105 & 0.035 & -0.015 & -0.003 \\
\hline Num. obs. & 263 & 263 & 261 & 260 & 244 & 258 \\
\hline RMSE & 0.146 & 0.190 & 0.202 & 0.178 & 0.206 & 0.198 \\
\hline
\end{tabular}


rule interactions are significant in Trials 2 and 3, explaining that the rating rule seems to reinforce the response to to ratings.

A second possibility is that experimental subjects may respond to star rating here because they wish to please the experimenter, a response known as the experimenter demand effect [Zizzo, 2010]. In our experiment, this behavior has real consequences, as blind adherence to the rating lowers the expected payoff in some treatments. The question of whether subjects follow guidance against their financial interest, however, is precisely the point of this study. This mirrors the possibility that, in practice, investors invest in accord with ratings (for example) simply because those ratings are supplied by an advisor or a ratings firm. We conclude that ratings affect performance.

The response to ratings relates to the general question of how subjects respond to presentation of information. An investor making an investment decision will examine advertisements, literature, reports, and possibly data about investment products and strategies. There is evidence that presentation of this information, including ratings, affects investment decisions for reasons unrelated to the economic characteristics of the investment.

Several papers look explicitly at the effects of ratings:

- Chen et al. [2014] examine split-rated bonds (i.e., those where rating agencies disagree about the bond rating) for which a bond index redefinition changed their status as investment grade. They show that bond yields changed in response to this purely mechanical redefinition. Because there was no new information about the bond, this real-world experiment resembles our assignment of stars, and, as with our experiment, finds real effects.

- In a related vein, Del Guercio and Tkac [2008] and Reuter and Zitzewitz [2015] examine whether equity mutual fund flows respond to Morningstar rating changes. Del Guercio and Tkac [2008] find that an increase in the star rating of a fund is accompanied by an inflow of funds, even after controlling for historical return characteristics. Reuter and Zitzewitz [2015], in a study of size and performance, also document a relationship between the rating and flows. Our findings are broadly consistent with theirs, but the settings are different. 
Because they use aggregate investment data, neither study can distinguish between existing investors changing their holdings in response to a ratings change (the intensive margin) and new investors attracted to a newly higher rating (the extensive margin). For the same reason, neither can examine investor heterogeneity. Our study examines the intensive margin, examining subjects in a given treatment who either see star ratings or not, and then comparing subjects across treatments. With both papers there is also the possibility that investors believe ratings convey real information about expected returns. ${ }^{29}$ In this regard, the findings in Chen et al. [2014] are more purely about rating changes. Finally, responses to ratings changes for a given fund does not address whether investors are misled by cross-category comparisons of ratings.

- Our experiment is complementary to that in Bateman et al. [2016], who vary the presentation of investment characteristics when asking subjects to rank portfolios. We leave the presentation unchanged, but find effects nevertheless.

Other papers consider the number of funds offered as an element of presentation.

- Benartzi and Thaler [2001] posit that investors choosing funds in a retirement account naively diversify using a $1 / N$ rule (investing equal amounts in offered assets). Huberman and Jiang [2006], however, find that investors are less inclined to diversify naively as the number of investments increases.

- More recently, Massa et al. [2015] examine a variant of the $1 / \mathrm{n}$ rule and find that investors invest more in a style (e.g., Asian funds) when there are more funds represented in that style.

We do not alter offerings and have the same number of offerings in each category. However, even in our simple context with a relatively small number of funds, we find no evidence for a $1 / \mathrm{n}$ rule.

\footnotetext{
${ }^{29}$ Del Guercio and Tkac [2008] report that investing only in five-star funds produces a positive risk-adjusted excess return in their sample, making it difficult to rule out the possibility that Morningstar rankings do convey information. See also Blake and Morey [2000].
} 
However, subjects do invest across more assets than is optimal. ${ }^{30}$

\subsection{Financial Knowledge}

We find that subjects who are more financially literate preform better in the baseline trial, but are still affected by categorization. The effect of financial literacy on performance is consistent with results in numerous papers. Among papers demonstrating positive effects of financial literacy are Bernheim et al. [2001], Bernheim and Garrett [2003], and Lusardi and Mitchell [2007]. In an experiment, Anderson and Settle [1996] also show significant effects of prior financial knowledge. The most direct evidence relating intelligence and financial performance is from Grinblatt et al. [2011], who find using Finnish data that that a higher IQ is associated with greater stock market participation and a higher Sharpe ratio. Our results are consistent with this: subjects with higher knowledge invest in portfolios with significantly higher Sharpe ratios. However, higher knowledge does not appear to mitigate the ratings effect we document here.

\subsection{Cognitive Limitations and Decision-making Biases}

Numerous studies have shown that subjects have computational limitations and exhibit biases. Most relevant are studies finding that subjects can be affected by irrelevant information. Edgell et al. [1996] list a range of areas in psychology where irrelevant information affects behavior. Examples include sunk costs [Thaler, 1980], random information signals [Tversky and Kahneman, 1974] and extra information not pertinent to the decision [Camerer et al., 1989]. Subjects also have trouble ignoring irrelevant alternatives. The failure of the independence axiom is well documented in general contexts (e.g., see Davis and Holt [1993]). In an investment environment, Herne [1999] shows how a "decoy" gamble can affect choices across gambles. Our results are similar, but distinct, from the prior research. Subjects are affected by something that should not affect behavior.

\footnotetext{
${ }^{30}$ Other papers that look at presentation effects include [Weber et al., 2005, Ibrekk and Morgan, 1987]; see also discussions in Tversky and Kahneman [1981, 1986]. Anderson and Settle [1996] show that both the form and amount of information affect choices.
} 
However, in our case, ratings do not convey irrelevant information nor do they make the decision environment more complicated. Ratings are merely redundant, yet still effect choices.

\subsection{Portfolio Choices}

We find that subjects on average tilt towards optimal portfolio choices, but with considerable variation. In general, research mimicking real-world portfolio decision-making has found that subjects inappropriately extrapolate from historical data [Moore et al., 1999], have difficulty forming efficient portfolios, [Kroll et al., 2003], and do not properly account for asset correlation [Kroll et al., 1988]. Our design removes many of these factors to focus entirely on ratings effects. However, our Trial 1 data does shed some light on these issues: in the absence of historical data when subjects do not need to account for correlation, subject choices tend toward relatively efficient investments, with the heaviest investments in A and B.

\section{Conclusion}

We study the effect of categorization and ratings on investment performance in an asset allocation experiment. Subjects allocate funds across investments for which they are shown full information about the distribution of returns. Subjects perform well in the initial trial, with experience and financial knowledge both associated with better performance. When subjects are shown the same information but with the addition of ordinal ratings, performance deteriorates for those in categorized treatments. We do not find that knowledge and experience mitigate this effect.

We conclude that both categorized and uncategorized ratings have drawbacks. Categorization takes into account that some investments cannot be directly compared and permits ratings of like against like. But using a common rating system across categories can implicitly create the kind of comparison that categorization was designed to avoid.

Our results have obvious relevance for investors choosing allocations in a defined contribution pension plan. Typically such plans offer participants a small number of funds in different categories 
along with supplementary information such as Morningstar ratings, a presentation (asset description plus stars) that broadly resembles our experimental format. Surprisingly, star ratings in our experiment don't change subject behavior except when inconsistent with choices subjects have already made without the help of ratings. This suggests that a number of subjects were competent at the allocation task and reinforces the desirability of continuing to study the effect on investment decisions of information presentation.

In addition to their widespread use in finance, inter-category ratings are ubiquitous in other realms. For example, ratings are used for beverages and foods. Wines in very different categories are rated on the same 100-point scale. In the NuVal system, nutritional information for foods is collapsed to a 100-point scale even though the foods may have high or low score for different reasons and may not be comparable. Academic performance is another example, with grades commonly compared across majors and schools, even though the difficulty, level of competition, and general grading policies may be quite different for different majors and institutions.

At a minimum, our results reaffirm the need to be careful when providing tools to assist in decision-making. 


\section{References}

George A Akerlof and William T Dickens. The economic consequences of cognitive dissonance. American Economic Review, 72(3):307-319, 1982.

Barry F. Anderson and John W. Settle. The influence of portfolio characteristics and investment period on investment choice. Journal of Economic Psychology, 17(3):343-358, 1996.

Hazel Bateman, Loretti I Dobrescu, Ben R Newell, Andreas Ortmann, and Susan Thorp. As easy as pie: How retirement savers use prescribed investment disclosures. Journal of Economic Behavior E Organization, 121:60-76, 2016.

Shlomo Benartzi and Richard H. Thaler. Naive diversification strategies in defined contribution saving plans. American Economic Review, 91(1):79-98, 2001.

Joyce Berg, John Dickhaut, and Kevin McCabe. Risk preference instability across institutions: A dilemma. Proceedings of the National Academy of Sciences of the United States of America, 102 (11):4209-4214, 2005.

Joyce E. Berg, John W. Dickhaut, and Thomas A. Rietz. Preference reversals: The impact of truth-revealing monetary incentives. Games and Economic Behavior, 68(2):443-468, 2010.

B. Douglas Bernheim and Daniel M. Garrett. The effects of financial education in the workplace: Evidence from a survey of households. Journal of Public Economics, 87(7-8):1487-1519, August 2003.

B. Douglas Bernheim, Daniel M. Garrett, and Dean M. Maki. Education and saving: The longterm effects of high school financial curriculum mandates. Journal of Public Economics, 80(3): 435-465, June 2001.

Christopher R. Blake and Matthew R. Morey. Morningstar ratings and mutual fund performance. Journal of Financial and Quantitative Analysis, 35(03):451-483, 2000. ISSN 1756-6916. 
Marshall E. Blume. An anatomy of morningstar ratings. Financial Analysts Journal, 54(2):19-27, 1998.

Colin Camerer, George Loewenstein, and Martin Weber. The curse of knowledge in economic settings: An experimental analysis. Journal of Political Economy, 97(5):1232-1254, October 1989.

John Y. Campbell. Household finance. Journal of Finance, LXI(4):1553-1604, August 2006.

Zhihua Chen, Aziz A. Lookman, Norman Schürhoff, and Duane J. Seppi. Rating-based investment practices and bond market segmentation. Review of Asset Pricing Studies, 4(2):163-205, 2014.

Douglas D. Davis and Charles A. Holt. Experimental economics. Princeton Univ Pr, 1993.

Diane Del Guercio and Paula A. Tkac. The effect of Morningstar ratings on mutual fund flow. Journal of Financial and Quantitative Analysis, 43(4):907-936, December 2008.

S.E. Edgell, N.J. Castellan Jr, R.M. Roe, J.M. Barnes, P.C. Ng, R.D. Bright, and L.A. Ford. Irrelevant information in probabilistic categorization. Journal of Experimental Psychology: Learning, Memory, and Cognition, 22(6):1463, 1996.

Mark Grinblatt, Matti Keloharju, and Juhani Linnainmaa. Iq and stock market participation. Journal of Finance, 66(6):2121-2164, December 2011.

K. Herne. The effects of decoy gambles on individual choice. Experimental Economics, 2(1):31-40, 1999.

Gur Huberman and Wei Jiang. Offering vs. choice in $401(\mathrm{k})$ plans: Equity exposure and number of funds. Journal of Finance, 61(2):763-801, 2006.

Harald Ibrekk and M. Granger Morgan. Graphical communication of uncertain quantities to nontechnical people. Risk Analysis, 7(4):519-529, 1987. 
Daniel Kahneman, Jack L Knetsch, and Richard H Thaler. Experimental tests of the endowment effect and the coase theorem. Journal of Political Economy, pages 1325-1348, 1990.

Yoram Kroll and Haim Levy. Further tests of the separation theorem and the capital asset pricing model. American Economic Review, 82(3):664-670, 1992.

Yoram Kroll, Haim Levy, and Natalie Alisof. "Homemade leverage:" theory versus experimental evidence. Journal of Portfolio Management, 31(1):84-93, 2003.

Yoram Kroll, Haim Levy, and Amnon Rapoport. Experimental tests of the separation theorem and the capital asset pricing model. American Economic Review, 78(3):500-519, June 1988.

Annamaria Lusardi and Olivia S. Mitchell. Baby boomer retirement security: The roles of planning, financial literacy, and housing wealth. Journal of Monetary Economics, 54(1):205-224, January 2007.

Massimo Massa, Andrei Simonov, and Anders Stenkrona. Style representation and portfolio choice. Journal of Futures Markets, 23:1-25, March 2015.

Robert C. Merton. Optimum consumption and portfolio rules in a continuous-time model. Journal of Economic Theory, 3(4):373-413, December 1971.

Robert C Merton. An intertemporal capital asset pricing model. Econometrica, 41(5):867-887, September 1973.

Don A. Moore, Terri R. Kurtzberg, Craig R. Fox, and Max H. Bazerman. Positive illusions and forecasting errors in mutual fund investment decisions. Organizational Behavior and Human Decision Processes, 79(2):95-114, 1999.

Morningstar. The morningstar rating for funds. Technical report, Morningstar, Inc., 2008. URL http://corporate.morningstar.com/US/documents/MethodologyDocuments/ FactSheets/MorningstarRatingForFunds_FactSheet.pdf. 
Kenneth Oliven and Thomas A. Rietz. Suckers are born but markets are made: Individual rationality, arbitrage, and market efficiency on an electronic futures market. Management Science, 50(3):336-351, 2004.

Matthew Rabin. Risk aversion and expected-utility theory: A calibration theorem. Econometrica, 68(5):1281-1292, September 2000.

Jonathan Reuter and Eric Zitzewitz. How much does size erode mutual fund performance? a regression discontinuity approach. Unpublished, Boston College, July 2015.

Annika E. Sunden and Brian J. Surette. Gender differences in the allocation of assets in retirement savings plans. American Economic Review, pages 207-211, 1998.

Richard Thaler. Toward a positive theory of consumer choice. Journal of Economic Behavior $\mathcal{E}$ Organization, 1(1):39-60, 1980.

A. Tversky and D. Kahneman. Judgment under uncertainty: Heuristics and biases. Science, 185 (4157):1124-1131, 1974.

Amos Tversky and Daniel Kahneman. The framing of decisions and the psychology of choice. Science, 211(4481):453-458, 1981.

Amos Tversky and Daniel Kahneman. Rational choice and the framing of decisions. Journal of Business, 59(4):251-278, 1986.

Elke U. Weber, Niklas Siebenmorgen, and Martin Weber. Communicating asset risk: How name recognition and the format of historic volatility information affect risk perception and investment decisions. Risk Analysis, 25(3):597-609, 2005.

Daniel John Zizzo. Experimenter demand effects in economic experiments. Experimental Economics, 13(1):75-98, 2010. 


\section{Internet Appendices}

\section{A Additional Tables}

Table A1 shows the order, by trial, in which investments are displayed.

Table A1: Order of display of assets in each trial

\begin{tabular}{ccccccc} 
Trial & Asset 1 & Asset 2 & Asset 3 & Asset 4 & Asset 5 & Assset 6 \\
\hline Initial Baseline & A & B & C & D & E & F \\
Rated & D & F & E & C & A & B \\
Self-rated & B & C & A & E & D & F \\
Final Baseline & F & E & D & C & B & A \\
\hline
\end{tabular}

Table A2 shows correlations for gender, taking the initial bet, knowledge, and experience.

Table A2: Correlations for subject characteristics. All correlations are significant with the exception of that between experience and the risk preference bet.

\begin{tabular}{rrrrr}
\hline & Female & Bet & Knowledge & Experience \\
\hline Female & 1.00 & 0.17 & -0.27 & -0.37 \\
Bet & 0.17 & 1.00 & -0.20 & -0.09 \\
Knowledge & -0.27 & -0.20 & 1.00 & 0.43 \\
Experience & -0.37 & -0.09 & 0.43 & 1.00 \\
\hline
\end{tabular}

Table A3 shows cash holdings across trials, broken down by whether subjects were in the treatmnet in which they were told the ranking rule.

Table A4 shows how subjects rated the assets in the different treatments. 
Table A3: Cash holdings in each trial, split by whether subjects are told the rating rule in the self-rated trial. Trial numbers indicate the baseline (1), the rated trial (2), the self-rated trial (3), and the final baseline (4).

\begin{tabular}{crrrrrrrr} 
& \multicolumn{10}{c}{ Trial } \\
\cline { 2 - 8 } & \multicolumn{1}{c}{ Rating Rule Not Given } & \multicolumn{4}{c}{ Rating Rule Given } \\
\hline Cash holding & 1 & 2 & 3 & 4 & 1 & 2 & 3 & 4 \\
\hline 0 & 108 & 104 & 96 & 100 & 106 & 108 & 102 & 110 \\
1 & 2 & 9 & 6 & 13 & 8 & 10 & 11 & 6 \\
2 & 10 & 5 & 7 & 11 & 8 & 4 & 8 & 3 \\
3 & 4 & 0 & 4 & 4 & 1 & 3 & 3 & 7 \\
4 & 2 & 10 & 2 & 0 & 2 & 1 & 2 & 0 \\
5 & 2 & 1 & 0 & 3 & 0 & 2 & 0 & 0 \\
6 & 4 & 2 & 4 & 1 & 3 & 1 & 1 & 1 \\
7 & 0 & 1 & 0 & 0 & 3 & 1 & 0 & 2 \\
8 & 0 & 0 & 0 & 0 & 1 & 1 & 2 & 1 \\
9 & 0 & 0 & 0 & 0 & 0 & 0 & 0 & 0 \\
10 & 0 & 1 & 0 & 0 & 0 & 0 & 0 & 0 \\
11 & 0 & 0 & 0 & 0 & 0 & 0 & 0 & 0 \\
12 & 1 & 0 & 14 & 1 & 1 & 2 & 4 & 3 \\
\hline
\end{tabular}


Table A4: Fraction of subjects assigning a given rating in the self-ranked trial, by treatment. The ratings shown to subjects in the Ranked trial are in bold. Ratings of subjects in the categorized treatment are in Panel A, and ratings of subjects in the non-categorized treatement are in Panel B. There were 67 subjects in each treatment in Panel A, and 66 subjects in each treatment in Panel B.

A: Categorized Treatment

\begin{tabular}{lrrrrrr} 
& \multicolumn{2}{c}{ Rank rule given } & \multicolumn{3}{c}{ Rank rule not given } \\
\hline Asset & 1 & 2 & 3 & 1 & 2 & 3 \\
\hline A & 0.12 & 0.10 & $\mathbf{0 . 7 8}$ & 0.12 & 0.48 & $\mathbf{0 . 4 0}$ \\
B & 0.03 & $\mathbf{0 . 8 7}$ & 0.10 & 0.04 & $\mathbf{0 . 4 8}$ & 0.48 \\
C & $\mathbf{0 . 8 5}$ & 0.03 & 0.12 & $\mathbf{0 . 8 4}$ & 0.04 & 0.12 \\
D & 0.13 & 0.03 & $\mathbf{0 . 8 4}$ & 0.07 & 0.03 & $\mathbf{0 . 9 0}$ \\
E & 0.03 & $\mathbf{0 . 9 4}$ & 0.03 & 0.04 & $\mathbf{0 . 9 4}$ & 0.01 \\
F & $\mathbf{0 . 8 4}$ & 0.03 & 0.13 & $\mathbf{0 . 8 8}$ & 0.03 & 0.09
\end{tabular}

B: Non-categorized Treatment

\begin{tabular}{lrrrrrr} 
& \multicolumn{3}{c}{ Rank rule given } & \multicolumn{3}{c}{ Rank rule not given } \\
\hline Asset & 1 & 2 & 3 & 1 & 2 & 3 \\
\hline A & 0.05 & 0.03 & $\mathbf{0 . 9 2}$ & 0.06 & 0.14 & $\mathbf{0 . 8 0}$ \\
B & 0.05 & 0.02 & $\mathbf{0 . 9 4}$ & 0.02 & 0.06 & $\mathbf{0 . 9 2}$ \\
C & 0.08 & $\mathbf{0 . 8 9}$ & 0.03 & 0.32 & $\mathbf{0 . 6 5}$ & 0.03 \\
D & 0.03 & $\mathbf{0 . 9 5}$ & 0.02 & 0.05 & $\mathbf{0 . 8 2}$ & 0.14 \\
E & $\mathbf{0 . 8 6}$ & 0.11 & 0.03 & $\mathbf{0 . 6 5}$ & 0.27 & 0.08 \\
F & $\mathbf{0 . 9 4}$ & 0.00 & 0.06 & $\mathbf{0 . 9 1}$ & 0.06 & 0.03 \\
\hline
\end{tabular}




\section{B Experimental Instructions}

Here, we give the text of the Web pages used for this experiment for the baseline treatment. We footnote where there are differences between treatments. Separate instruction sets for each treatment are available by request. Web formatting differed slightly from the formatting below and the Web pages were interactive. Subjects used drop-down boxes to make allocation decisions and radio buttons to answer survey questions.

\section{General Instructions}

This is an experiment in the economics of decision making. The instructions are simple. If you follow them carefully and make good decisions, you might earn a considerable amount of money which will be mailed to you at the end of the experiment.

In stages of this experiment, you will be given cash that you can keep or you can invest all of it or portions of it in one or more investment alternatives. The amounts you invest in each alternative and some random draws will determine your payoffs from participating in this experiment. We will also ask you a series of questions about your preferences, knowledge and demographics.

\section{- Next Web Page}

\section{Descriptions of Investment Alternatives}

At different stages in this experiment you will be given cash that you can (a) keep or (b) can invest all of it or portions of it in one or more investment alternatives. This is called an allocation decision. The amounts you invest will be in $\$ 1$ increments. Each investment alternative will result in either a high return or a low return. A random draw will determine which occurs. Half of the time, the high return will occur and half of the time the low return will occur. The cash you keep always earns a zero return.

For each $\$ 1$ invested in an alternative, you will be paid $\$ 1$ times 1 plus the return that occurs. Returns will be expressed in percentage terms. So, for example, if the return that occurs is $80 \%$, 
you will be paid $\$ 1 \mathrm{x}(1+0.80)=\$ 1.80$ for each dollar invested in that alternative. That is, you get the original $\$ 1$ back plus $80 \%$ of a dollar, or 80 cents in additional return. If the return that occurs is $-30 \%$, then you will be paid $\$ 1 \mathrm{x}(1+(-0.30))=\$ 0.70$. That is, you lose $30 \%$, or 30 cents, of the original dollar invested. If you had invested $\$ 2$, you would have been paid $\$ 2 \mathrm{x}(1+0.80)=\$ 3.60$ or $\$ 2 \mathrm{x}(1+(0.30))=\$ 1.40$ if the high or low return had occurred, respectively.

Each investment alternative will be described to you by giving the high return, the low return, the average return and the range of returns in a table. Finally, you will be given a "Return/Risk" ratio which is the expected return divided by the range. For example, an investment alternative, say, "Alternative X" that has a high return of high return of $150 \%$ and a low return of $-50 \%$ would be described as:

\begin{tabular}{|l|l|}
\hline Alternative: & $\mathrm{X}$ \\
\hline High Return: & $150 \%$ \\
\hline Low Return: & $-50 \%$ \\
\hline Average Return: & $50 \%$ \\
\hline Range of Returns: & $200 \%$ \\
\hline Return/Risk Ratio: & 0.2500 \\
\hline
\end{tabular}

If you received the high return in this case, you would be paid $\$ 1 \mathrm{x}(1+1.5)=\$ 2.50$ for each $\$ 1$ invested. If you received the low return in this case, you would be paid $\$ 1 \mathrm{x}(1+(-0.50))=\$ 0.50$ for each $\$ 1$ invested. Recall, that the high return will occur half of the time and the low return will occur half of the time. Which actually occurs is determined by a random draw. In any given stage, you may be asked to allocate cash across several investments.

In a stage, if the high return occurs for one investment, the high return will occur for all investments in that stage. If the low return occurs for one investment, the low return will occur for all investments in that stage.

\section{Next Web Page \\ Descriptions of Investment Alternatives (continued)}


To see if you understand an investment alternative, please answer the following three questions about the investment alternative "Y" described by:

\begin{tabular}{|l|l|}
\hline Alternative: & $\mathrm{Y}$ \\
\hline High Return: & $210 \%$ \\
\hline Low Return: & $-80 \%$ \\
\hline Average Return: & $65 \%$ \\
\hline Range of Returns: & $290 \%$ \\
\hline Return/Risk Ratio: & 0.2241 \\
\hline
\end{tabular}

1. If the high return occurs for "Y", what return will occur for other investments in that stage?

(a) All other investments in that stage will return their respective "low" returns. Feedback if selected: "Recall that, in a given stage, either ALL investments return their respective 'high' returns or ALL investments return their respective 'low' returns. Please try a different answer."

(b) All other investments will return their respective "high" returns. Feedback if selected: "Correct. Proceed to question 2."

(c) The returns to other investments at that stage may be mixed with some "high" and some "low" returns. Feedback if selected: "Recall that, in a given stage, either ALL investments return their respective 'high' returns or ALL investments return their respective 'low' returns. Please try a different answer."

2. If you invest $\$ 3$ in this alternative and the high return occurs, how much will you be paid?

(a) \$2.10 Feedback if selected: "This is the gain on a $\$ 1$ investment, not the total amount paid to you. Please try a different answer."

(b) $\$ 3.10$ Feedback if selected: "This is the payment for a $\$ 1$ investment. Recall you are investing \$3. Please try a different answer." 
(c) \$6.30 Feedback if selected: "This is the gain on the $\$ 3$ investment, not the total amount paid to you. Please try a different answer."

(d) \$9.30 Feedback if selected: "Correct. Please continue to Question 3."

3. If you invest $\$ 2$ in this alternative, and the low return occurs, how much will you be paid?

(a) -\$0.80 Feedback if selected: "This is the loss on a $\$ 1$ investment, not the total amount paid to you. Please try a different answer."

(b) $\$ 0.20$ Feedback if selected: "This is the payment for a \$1 investment. Recall you are investing \$2. Please try a different answer."

(c) $-\$ 1.60$ Feedback if selected: "This is the loss on the $\$ 2$ investment, not the total amount paid. Please try a different answer."

(d) \$0.40 Feedback if selected: "Correct. Please continue to the next part of the experiment."

The continue button only becomes active after the answers are correct.

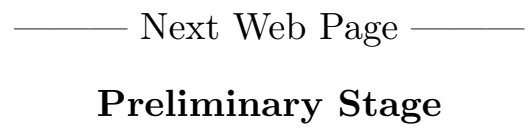

In this stage you have $\$ 1$ to allocate. You can either keep it or invest it in the following investment alternative:

\begin{tabular}{|l|l|l|l|}
\hline Alternative: & A & & \\
\hline High Return: & $100 \%$ & & \\
\hline Low Return: & $-100 \%$ & & \\
\hline Average Return: & $0 \%$ & & \\
\hline Range of Returns: & $200 \%$ & & \\
\hline Return/Risk Ratio: & 0.0000 & & Amount Kept \\
\hline Amount you Invest: & & & $=\$ 1$-Invested \\
\hline
\end{tabular}


When you are finished with your choice, click the "continue" button below. At the end of the experiment, a random draw will determine your payoff to this stage. This will become part of your earnings for the experiment.

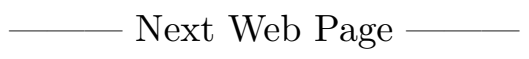

\section{Additional Instructions}

In the rest of the experiment, you will make several investment decisions. Each decision is a "stage" in the experiment.

In each stage, you will have $\$ 12$ to keep or invest. You can keep the $\$ 12$ or invest some or all of it in any of 6 investment alternatives in $\$ 1$ increments. You can invest the $\$ 12$ in whatever combination of investments and in whatever amounts you wish so long as the total investment is less than or equal to $\$ 12$. Any amount you do not invest will be kept for that stage and earn a zero return. The outcomes of any given stage will not affect the amount you have to invest in the next stage. You will always start each stage with a new $\$ 12$.

At the end of the experiment, we will randomly select one stage. Then, we will make a SINGLE random draw that will determine whether the gambles in that stage pay the high return or the low return. That is, either ALL investments in that stage will give you a high return or ALL of the investments will give the low return.

Earnings from this stage and random draw, together with earnings from the preliminary stage and the $\$ 5$ participation fee, will contribute to your earnings for the experiment.

Between stages and at the end of the experiment, you will be asked questions that will help us categorize your responses.

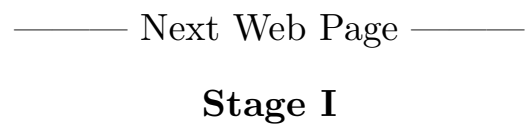

In this stage you have $\$ 12$ to allocate. You can either keep it or invest it in the following 
investment alternatives in $\$ 1$ increments. ${ }^{31}$

\begin{tabular}{|l|l|l|l|l|l|l|l|l|}
\hline Alternative: & A & B & C & D & E & F & \\
\hline High Return: & $130 \%$ & $185 \%$ & $125 \%$ & $200 \%$ & $225 \%$ & $190 \%$ & \\
\hline Low Return: & $30 \%$ & $15 \%$ & $-25 \%$ & $-20 \%$ & $-75 \%$ & $-90 \%$ & \\
\hline Average Return: & $80 \%$ & $100 \%$ & $50 \%$ & $90 \%$ & $75 \%$ & $50 \%$ & \\
\hline Range of Returns: & $100 \%$ & $170 \%$ & $150 \%$ & $220 \%$ & $300 \%$ & $280 \%$ & \\
\hline Return/Risk Ratio: & 0.8000 & 0.5882 & 0.3333 & 0.4091 & 0.2500 & 0.1786 & Amount Kept \\
\hline Amount you Invest: & & & & & & & = \$12-Invested \\
\hline
\end{tabular}

Please confirm your allocation before pressing continue.

When you are finished with your choice, click the "continue" button below. At the end of the experiment, we will randomly select one of these stages to play out. If this stage is chosen, a single random draw will determine the returns to ALL of the investment in this stage and, as a result, your payoff to this stage. This will become part of your earnings for the experiment.

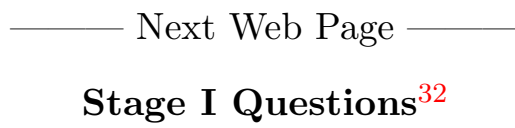

Please answer the following questions. Click the "Submit" button below to continue on to the next stage.

1. How satisfied are you with your allocation decision in this stage?

Very

Dissatisfied

1

23

Neutral

Very

Satisfied

2. Do you wish you could go back and change your decision?

\footnotetext{
${ }^{31}$ In treatments with categories, the table of alternatives in each stage was presented with three investments labeled "Category I" on the left and three labeled with "Category II" on the right with a blank column between them. The sentence "These alternatives have been categorized using a commonly used financial method." was added to the description.

${ }^{32}$ These questions were asked after each stage. We present them only once here for brevity.'
} 

(a) Yes
(b) No

3. How confused did you feel while making the allocation decision?

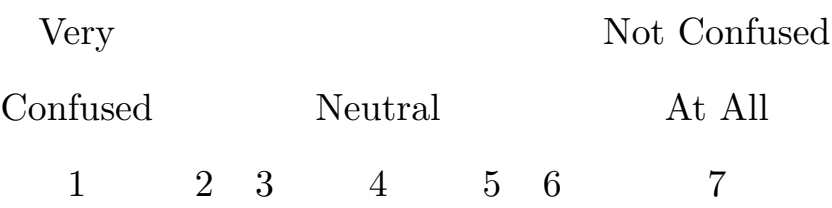

\section{Next Web Page}

\section{Stage II}

In this stage you have $\$ 12$ to allocate. You can either keep it or invest it in the following investment alternatives in $\$ 1$ increments. In this stage, we have ranked the investments according to a common method of ranking investments. ${ }^{33}$ Investments with more ${ }^{*}$ 's in the ranking line are ranked higher according to this criterion.

\begin{tabular}{|l|l|l|l|l|l|l|l|l|}
\hline Alternative: & $\mathrm{A}$ & $\mathrm{B}$ & $\mathrm{C}$ & $\mathrm{D}$ & $\mathrm{E}$ & $\mathrm{F}$ & \\
\hline High Return: & $200 \%$ & $190 \%$ & $225 \%$ & $125 \%$ & $130 \%$ & $185 \%$ & \\
\hline Low Return: & $-20 \%$ & $-90 \%$ & $-75 \%$ & $-25 \%$ & $30 \%$ & $15 \%$ & \\
\hline Average Return: & $90 \%$ & $50 \%$ & $75 \%$ & $50 \%$ & $80 \%$ & $100 \%$ & \\
\hline Range of Returns: & $220 \%$ & $280 \%$ & $300 \%$ & $150 \%$ & $100 \%$ & $170 \%$ & \\
\hline Return/Risk Ratio: & 0.4091 & 0.1786 & 0.2500 & 0.3333 & 0.8000 & 0.5882 & \\
\hline Ranking: & $* * *$ & $*$ & $* *$ & $*$ & $* * *$ & $* *$ & Amount Kept \\
\hline Amount you Invest: & & & & & & & = \$12-Invested \\
\hline
\end{tabular}

Please confirm your allocation before pressing continue.

When you are finished with your allocation, click the "continue" button below. As a reminder, at the end of the experiment, we will randomly select one of these stages to play out. If this stage

\footnotetext{
${ }^{33}$ In treatments where the ranking rule is given to subjects, this sentence was replaced with "In this stage, we have ranked the investments according to the Return/Risk ratio, which is a common method of ranking investments." The words "within categories" were added to the end of the appropriate sentence for treatments with categories.
} 
is chosen, a single random draw will determine the returns to ALL of the investments in this stage and, as a result, your payoff to this stage.

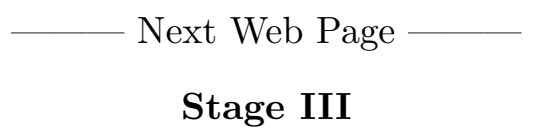

In this stage you have $\$ 12$ to allocate. You can either keep it or invest it in the following investment alternatives in $\$ 1$ increments. In this stage, we ask you to first rank the investments. Use the drop down boxes to assign 1, 2 or 3 stars to investments. 3 -star investments should be the investments with the highest rank, 1-star investments should be the investments with the lowest rank and 2-star investments should be in between. You are asked to assign two 3-star, two 2-star and two 1-star ratings. ${ }^{34}$

\begin{tabular}{|l|l|l|l|l|l|l|l|l|}
\hline Alternative: & A & B & C & D & E & F & \\
\hline High Return: & $185 \%$ & $125 \%$ & $130 \%$ & $225 \%$ & $200 \%$ & $190 \%$ & \\
\hline Low Return: & $15 \%$ & $-25 \%$ & $30 \%$ & $-75 \%$ & $-20 \%$ & $-90 \%$ & \\
\hline Average Return: & $100 \%$ & $50 \%$ & $80 \%$ & $75 \%$ & $90 \%$ & $50 \%$ & \\
\hline Range of Returns: & $170 \%$ & $150 \%$ & $100 \%$ & $300 \%$ & $220 \%$ & $280 \%$ & \\
\hline Return/Risk Ratio: & 0.5882 & 0.3333 & 0.8000 & 0.2500 & 0.4091 & 0.1786 & \\
\hline Ranking: & & & & & & & & Amount Kept \\
\hline Amount you Invest: & & & & & & & = \$12-Invested \\
\hline
\end{tabular}

When you are finished with your allocation, click the "submit rankings" button below. Then, you will be allowed to allocate cash.

Please confirm your allocation before pressing continue.

\footnotetext{
${ }^{34}$ In treatments where the ranking rule is given, this paragraph is replaced with "In this stage, we ask you to first rank the investments according to the return/risk ratio. Use the drop down boxes to assign 1,2 or 3 stars to investments. 3-star investments should be the investments with the highest return/risk ratio, 1-star investments should be the investments with the lowest return/risk ratio and 2-star investments should be in between. You are asked to assign two 3-star, two 2-star and two 1-star ratings." In both treatments with categories, the last sentence is replaced with "You are asked to assign one 3-star, one 2-star and one 1-star rating within each category of investments."
} 
When you are finished with your allocation, click the "continue" button below. As a reminder, at the end of the experiment, we will randomly select one of these stages to play out. If this stage is chosen, a single random draw will determine the returns to ALL of the investments in this stage and, as a result, your payoff to this stage.

\section{Next Web Page}

\section{Stage IV}

In this stage you have $\$ 12$ to allocate. You can either keep it or invest it in the following investment alternatives in $\$ 1$ increments.

\begin{tabular}{|l|l|l|l|l|l|l|l|l|}
\hline Alternative: & A & B & C & D & E & F & \\
\hline High Return: & $190 \%$ & $225 \%$ & $200 \%$ & $125 \%$ & $185 \%$ & $130 \%$ & \\
\hline Low Return: & $-90 \%$ & $-75 \%$ & $-20 \%$ & $-25 \%$ & $15 \%$ & $30 \%$ & \\
\hline Average Return: & $50 \%$ & $75 \%$ & $90 \%$ & $50 \%$ & $100 \%$ & $80 \%$ & \\
\hline Range of Returns: & $280 \%$ & $300 \%$ & $220 \%$ & $150 \%$ & $170 \%$ & $100 \%$ & \\
\hline Return/Risk Ratio: & 0.1786 & 0.2500 & 0.4091 & 0.3333 & 0.5882 & 0.8000 & Amount Kept \\
\hline Amount you Invest: & & & & & & & =\$12-Invested \\
\hline
\end{tabular}

Please confirm your allocation before pressing continue.

When you are finished with your allocation, click the "continue" button below. As a reminder, at the end of the experiment, we will randomly select one of these stages to play out. If this stage is chosen, a single random draw will determine the returns to ALL of the investments in this stage and, as a result, your payoff to this stage.

Next Web Page

\section{Knowledge and Demographic Surveys}

Next, we would like you to fill out brief demographic and knowledge surveys to help us classify the data. Your responses will be kept in a data file that does not include any identifying information. We will keep your participation in this research study confidential to the extent permitted by law. 
Taking part in the surveys is completely voluntary. Leave blank any questions you prefer not to answer. You won't be penalized or lose any benefits for which you otherwise qualify.

At the end of the surveys, we will randomly select one of stages 1 through 4 that you have completed and use your allocation decision from this stage and a random draw to determine your payoffs for this experiment.

Earnings from this stage and random draw, together with earnings from the preliminary stage and the $\$ 5$ participation fee, will contribute to your earnings for the experiment.

Press the "continue" button below to go on to the Knowledge Survey.

\section{Next Web Page}

\section{Knowledge Survey}

1. How would you classify your knowledge of financial markets? ${ }^{35}$

(a) No knowledge whatsoever

(b) Beginner level

(c) Intermediate level

(d) Advanced level

2. How much experience have you had with trading on organized financial markets? ${ }^{36}$

(a) Novice (Have never traded.)

(b) Limited (Have, for example, made some trades on my own account.)

(c) Experienced Amateur (Have traded a good deal for myself, friends or family.)

(d) Professional (Have been paid for trading.)

\footnotetext{
${ }^{35}$ Source: Variant (added the "No knowledge whatsoever" option) of IEM financial knowledge survey question from Oliven and Rietz [2004].

${ }^{36}$ Source: IEM financial knowledge survey question from Oliven and Rietz [2004].
} 
3. How many hours in a typical week do you spend following or trading on organized financial markets ${ }^{37}$
(a) None
(b) An hour or less
(c) Between 1 and 5 hours
(d) Between 5 and 10 hours
(e) More than 10 hours.

4. How do you rate your knowledge of investments relative to other people? ${ }^{38}$

(a) Much less knowledgeable

(b) Somewhat less knowledgeable

(c) About as knowledgeable

(d) Somewhat more knowledgeable

(e) Much more knowledgeable

5. What is compound interest? ${ }^{39}$

(a) Earning money on your principal and your interest.

(b) a complicated form of interest.

(c) A long term investment.

(d) A risk/return scenario.

6. What is an example of a low risk investment $?^{40}$

\footnotetext{
${ }^{37}$ Source: Variant (made into multiple choice question) of IEM financial knowledge survey question from Oliven and Rietz [2004].

${ }^{38}$ Source: New.

${ }^{39}$ Source: InvestNative Project Investment Quiz, question 4. http://www.investnative.org/test.html, accessed 08/19/2010.

${ }^{40}$ Source: InvestNative Project Investment Quiz, question 21. http://www.investnative.org/test.html, accessed $08 / 19 / 2010$.
} 
(a) Small cap stock.

(b) High yield "junk" bond.

(c) FDIC insured savings account.

(d) An international mutual fund focused on small Latin American airline companies.

7. If the value of your investment declines by $60 \%$, what subsequent percentage increase is needed to return to your original investment amount ${ }^{41}$
(a) $60 \%$.
(b) $120 \%$.
(c) $150 \%$.
(d) $180 \%$.

8. In general, stock mutual funds that are riskier tend to provide higher returns over time than stock mutual funds with less risk. ${ }^{42}$
(a) True.
(b) False.
(c) Don't know/Not sure.

9. Which of these investments have a risk of losing value? ${ }^{43}$

(a) Mutual funds

(b) Blue chip stocks

\footnotetext{
${ }^{41}$ Source: Pacific Life Investment Knowledge Quiz, question 4: http://www.pacificlife.com/Channel/Educational+Information/Calcu accessed 08/19/2010.

${ }^{42}$ Source: Financial Industry Regulatory Authority Investor Knowledge Quiz, question 7 : http://apps.finra.org/Quiz/1/investorquiz.aspx, accessed 08/19/2010.

${ }^{43}$ Source: Pacific Life Investment Knowledge Quiz, question 5: http://www.pacificlife.com/Channel/Educational+Information/Calcu accessed 08/19/2010.
} 
(c) High-yield bonds

(d) They all have risk of losing value

10. What is diversification? ${ }^{44}$

(a) A way to reduce risk.

(b) Investing in different things, such as stocks, bonds, savings, property, etc.

(c) Having an asset allocation that spreads your investment among different asset classes.

(d) All of the above.

11. Common stocks always provide higher returns than bonds or money market investments. ${ }^{45}$

(a) True.

(b) False.

(c) Don't know.

12. Asset allocation is a form of: ${ }^{46}$
(a) Repayment.
(b) Diversification.
(c) Capital.

13. Generally, a portfolio that has $80 \%$ of its assets invested in stocks would be best suited for: ${ }^{47}$

(a) An 18-year-old using the assets to pay for college expenses over the next 4 years.

\footnotetext{
${ }^{44}$ Source: InvestNative Project Investment Quiz, question 11. http://www.investnative.org/test.html, accessed 08/19/2010.

${ }^{45}$ Source: Vanguard Investment Knowledge Quiz, question 3: https://personal.vanguard.com/us/InvestmentKnowledge, accessed 08/19/2010.

${ }^{46}$ Source: InvestNative Project Investment Quiz, question 14. http://www.investnative.org/test.html, accessed 08/19/2010.

${ }^{47}$ Source: Vanguard Investment Knowledge Quiz, question 19: https://personal.vanguard.com/us/InvestmentKnowledge, accessed 08/19/2010.
} 
(b) A 35-year-old investing for retirement.

(c) A 75-year-old investing for income and capital preservation.

(d) None of the above.

(e) Don't know.

\section{Next Web Page \\ Demographic Survey}

1. What is your gender?
(a) Female
(b) Male

2. What is your age?
(a) Under 30 Years Old.
(b) 30-39 Years Old.
(c) 40-49 Years Old.
(d) 50 Year Old and Older.

3. What is your current marital status?
(a) Married.
(b) Not Married.

4. Do you have children?
(a) Yes.
(b) No. 
5. What is your current annual income?
(a) $\$ 0-\$ 19,999$.
(b) $\$ 20,000-\$ 29,999$.
(c) $\$ 30,000-\$ 39,999$.
(d) $\$ 40,000-\$ 69,999$.
(e) Greater that $\$ 60,000$.
(f) Would rather not say.

6. What is the highest educational degree you have achieved?
(a) High School
(b) Bachelor's.
(c) Master's
(d) Doctorate.
(e) Other.

7. What is or was your college major (most recent degree if you are not currently a student)?
(a) Business.
(b) Social Science.
(c) Humanities.
(d) Natural Science.
(e) Mathematics or Engineering.
(f) Other.
(g) None. 


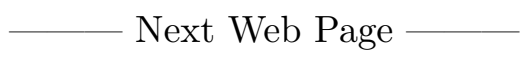

\section{Final Question}

After outcomes and payments have been determined, subjects answer the following final question:

1. How satisfied are you with your allocation decision in the stage that was selected to determine your payoffs?

Very

Dissatisfied

1

Neutral

Very

Satisfied

$\begin{array}{lll}5 & 6 & 7\end{array}$ 